\title{
إطلاق الجنسية الأصلية من جهة الأم في ظل المتغيرات الداخلية والدولية
}

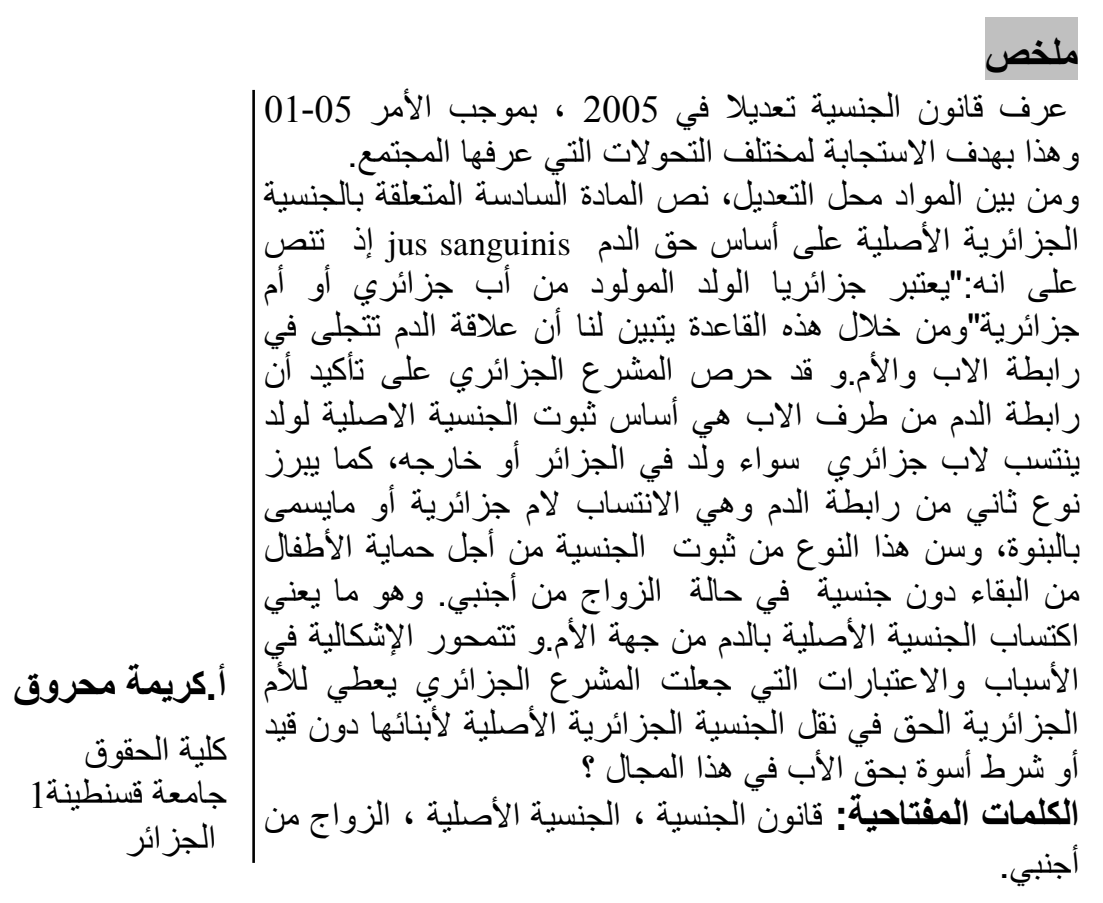

\section{مقدمة}

تعتبر الجنسية الاصلية المحدد الرئيسي للمواطنين

\section{Résumé} été introduites à la loi de la citoyenneté qui permet aux

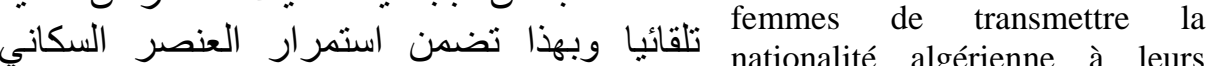
enfants nés de mariages avec des

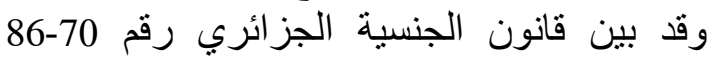
étrangers.

L'adoption de cette loi est une preuve de citoyenneté des enfants et de l'acquisition de la

nationalité d'origine de leur mère. Mots clés : Loi de la رئيسيتين وهما: citoyenneté, mariage mixte,

حالة رابطة الدم: تسذد الجنسية الاصلية بناء على enfants. 
نسبة الفرد لاصدول وأجداد ينتسبون بدور هم للجزائر وبعبارة أدل وأوضح رابطة الادم، وحالة رابط الإقليه.

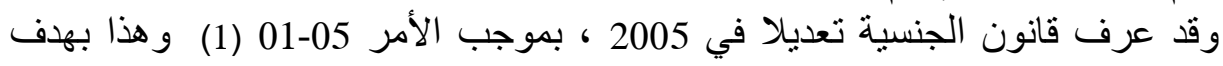

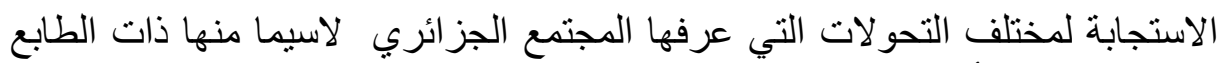

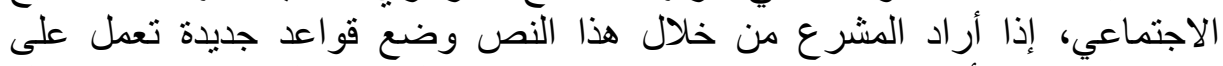

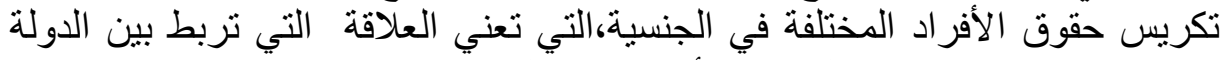

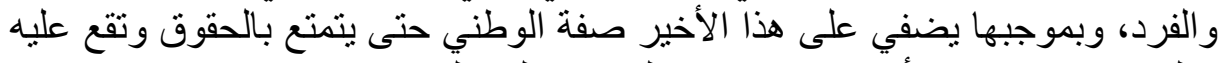

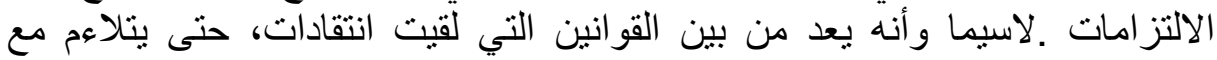

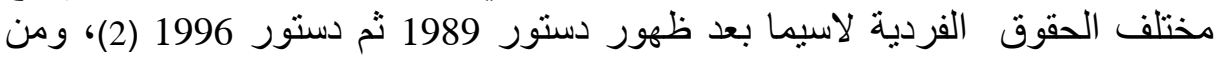

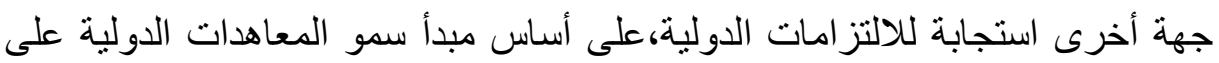

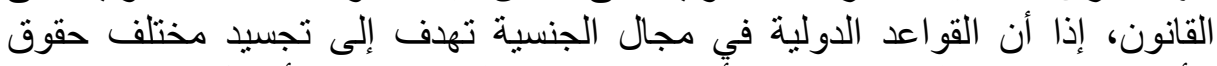
الأفراد سواء حق التمتع بالجنسية أُو المساواة بين الجنسين في الأعمال بها ـومن بين

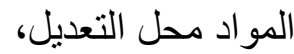

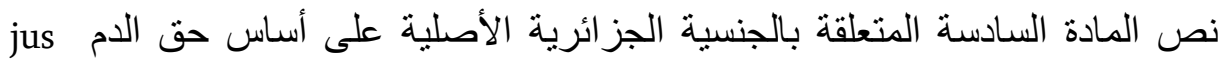

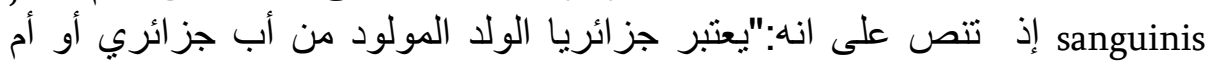

جز ائرية". (3) - ج

ومن خلال هذه القاعدة يتبين لنا أن علاقة الدم تتجلى في رابطة الاب والأم.

وقد حرص المشرع الجزائري على تأكيد أن رابطة الدم من طرف الاب هي أساس

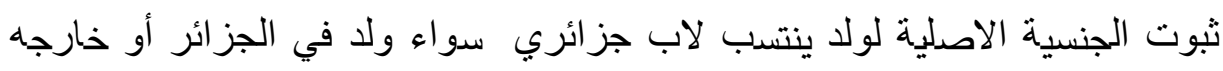

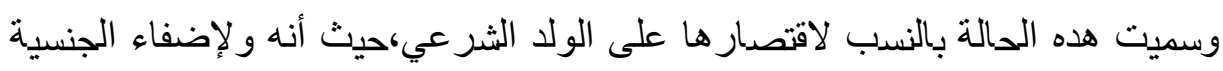

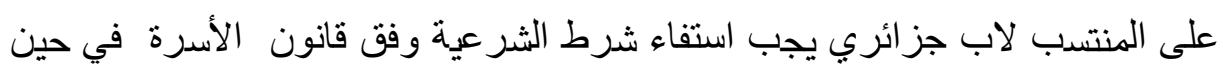

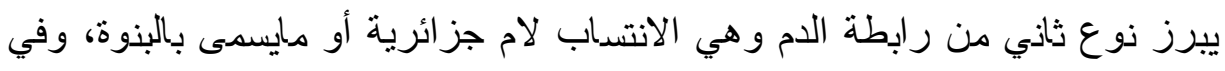

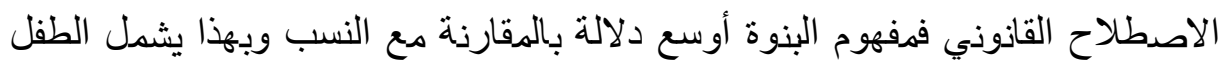

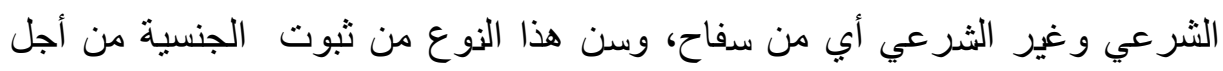

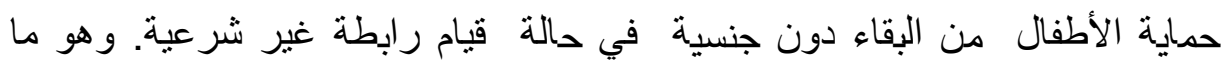
يعني اكتساب الجنسية الأصلية بالدم من جهة الأم.

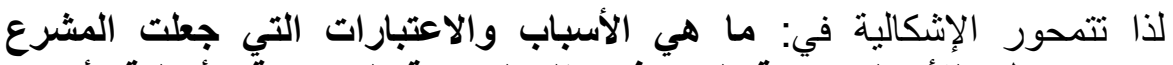

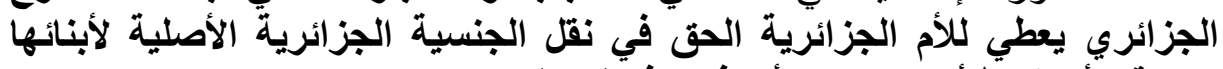
دون قيد أو شرط أسوة بحق الأب في هذا المجال ؟. 
ومدى فعالية وملائمة هذا التعديل للتوفيق بين مختلف المصالح الداخلية والقواعد ذات الطابع الدولي في مجال الجنسية؟ .

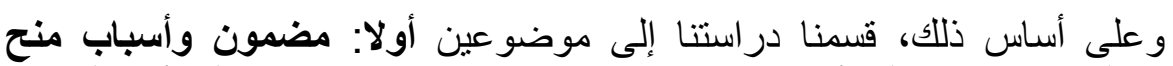
الجنسية بالدم من جهة الأم.ثانيا: محاذير تكريس قاعدة الأئ منح الجنسية الأصلية بالام من جهة الأم والحلول المن جلمة الامرة

المبحث الأول:مضمون وأسباب تشريع منح الجنسية الأصلية بالدم من جهة الأم: بثير موضوع إعادة النظر في قواعد الجنسية الجزائرية الأصلية خاصة أحكام

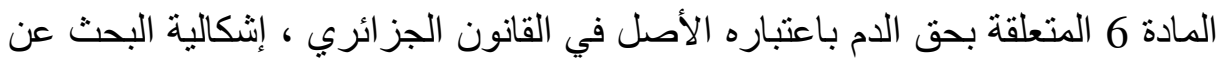

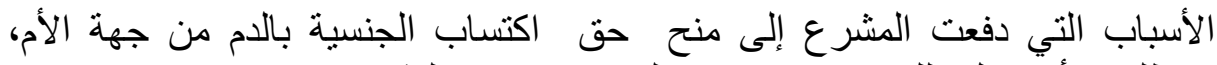

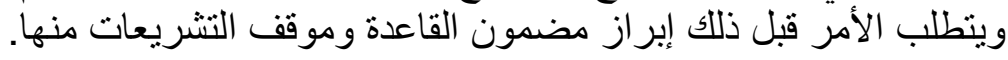
المطلب الأول- مضمون القاعدة و موقف التشريعات منها: الفرع الأول- تعريف رابطة الدم بمضمونها المطلق أو الثنائي الجاتب:

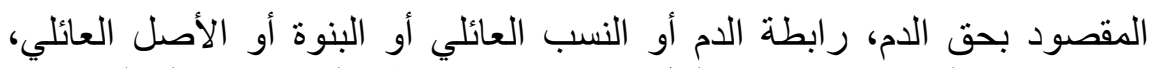

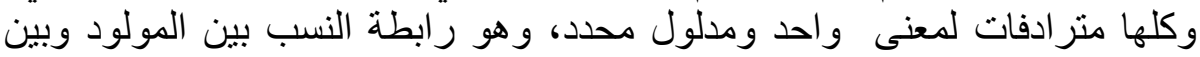

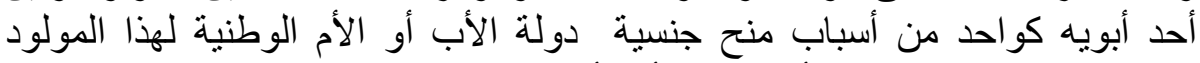

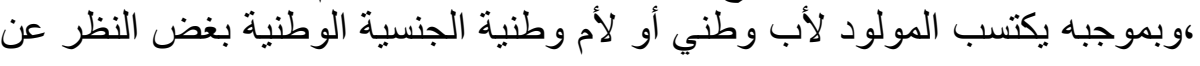

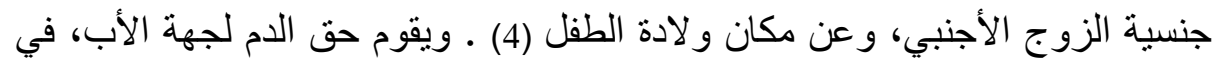

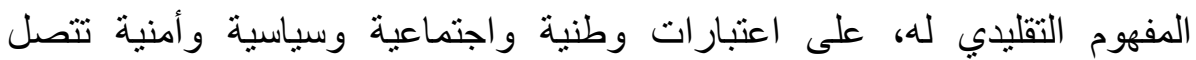

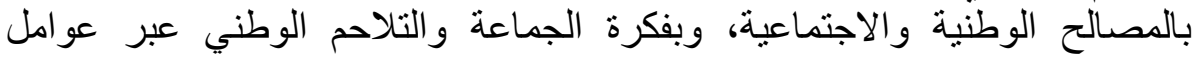

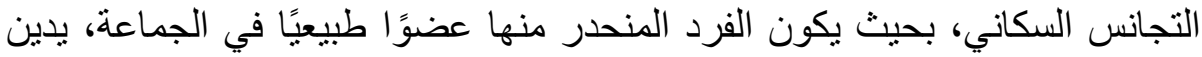

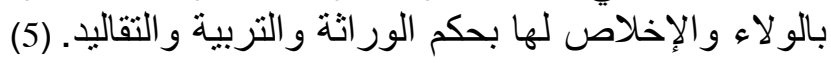

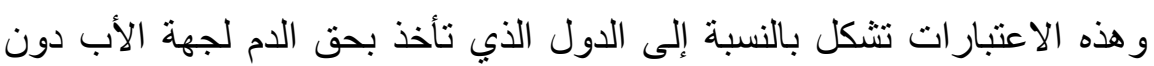

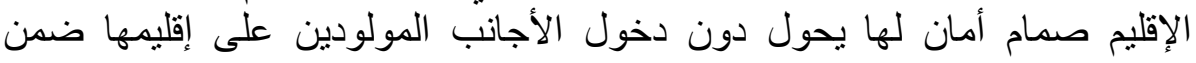
صفوف مواطنيها .كما تسمح لها من جهة أخرى بالمحافظة على ارتباط أبنائها

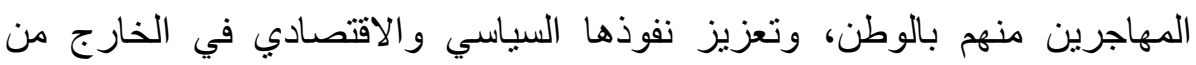
خلالهم. (6) (1)

الفرع الثاني-موقف التشريعات من رابطة الام: اختلفت الدول الحديثة في التعامل مع ضابط البنوة أو النسب فيما يخص تحديد النسب الذي يعتد به لنقل الجنسية إلى المولود ـهل المقصود به النسب لجهة الأب 
دون الأم ..... ؟ أم العبرة بالنسب إلى كل منهما معًاٌ أي للأبوين الوطنيين، أم لأي

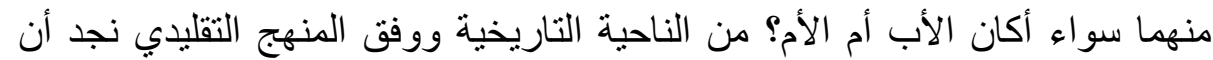

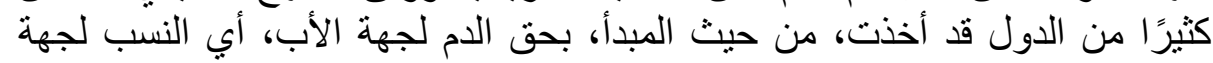

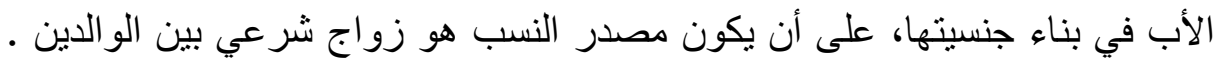

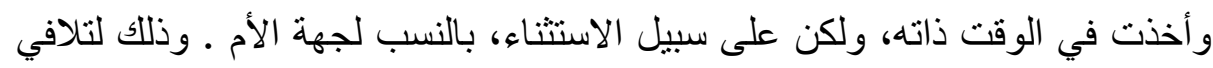

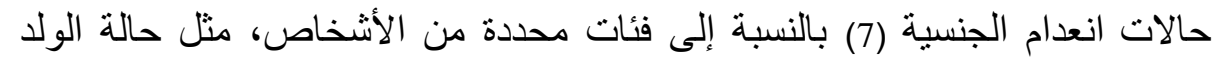

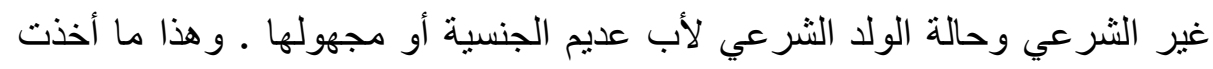

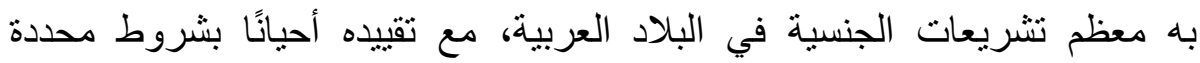

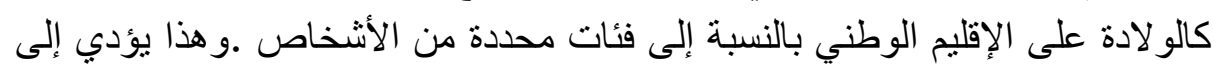

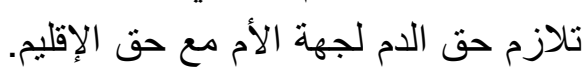

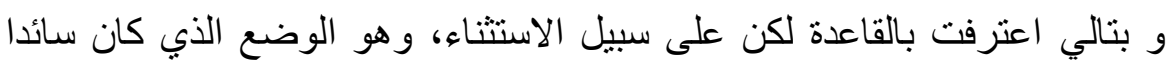

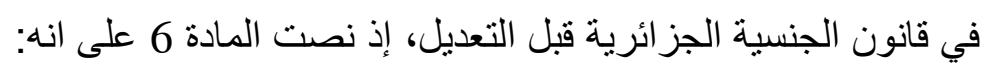

$$
\begin{aligned}
& \text { "يعتبر من الجنسية الجزائرية بالنسب: }
\end{aligned}
$$

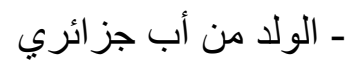

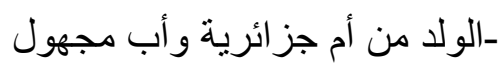

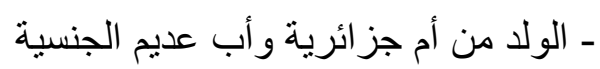

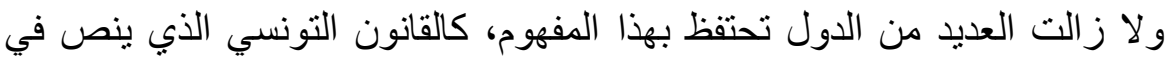
الفصل السادس من قانون الجنسية على انه: "يكون تونسيا

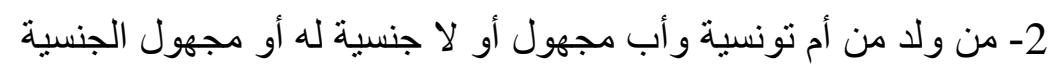

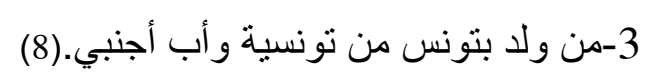

القانون السوري بموجب المادة 3 من قانون الجنسية التي تتص على انه :" بعتبر

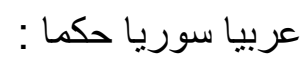

ب- من ولد في القطر من أم عربية سورية ولم تثبت نسبته إلى أبيه قانونا " (9)،

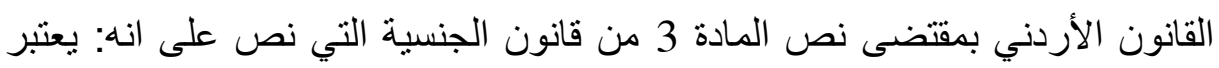

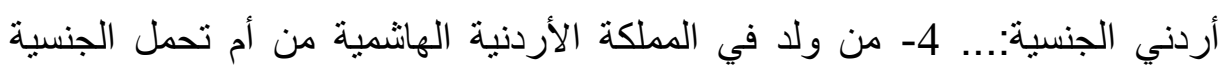

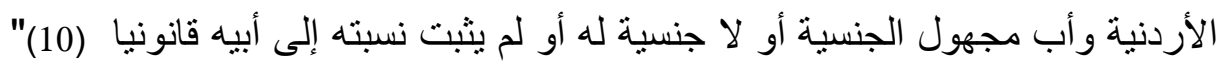


و القانون المصري بموجب نص المادة 2 التي تتص على انه مصريا: ...2-من ولد في مصر من أم مصرية ومن أب مجهول الجنسية أو لا جنسية له 3- من ولد في مصر

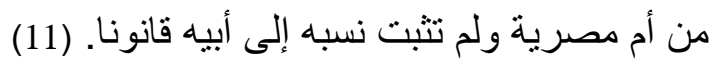

ولم ترفض هذه التشريعات فكرة إطلاق قاعدة حق الدم من جهة الأم إلا استتادا إلى لـى المشاكل التي تنتج عنها و التي سنر اها لاحقا.

وجانب أخر من التشريعات لا تضع أي قيد على حق اكتساب الجنسية بالدم من التصن

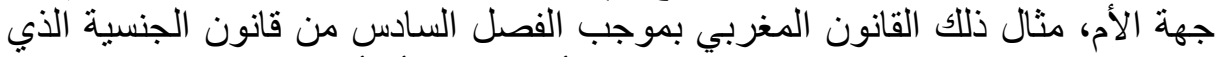

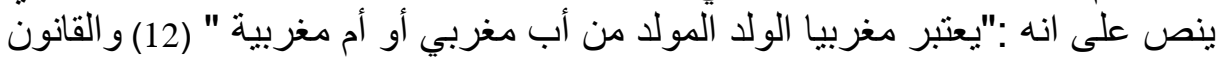

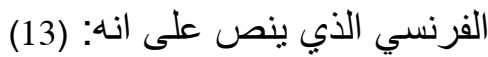

«Est français l'enfant dans l'un des parents est français »

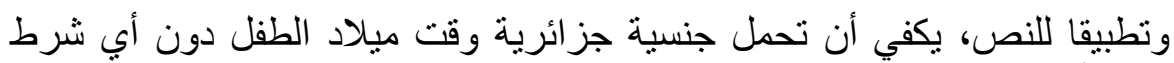

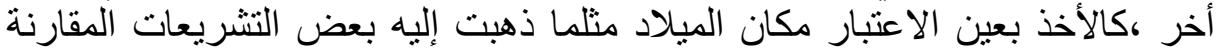

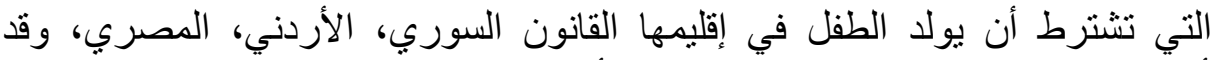

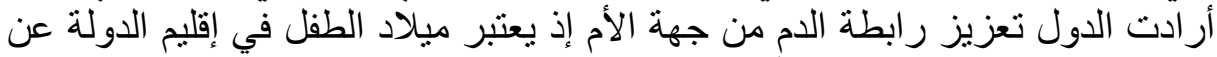

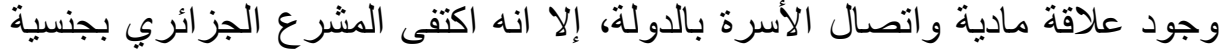
الأم الجزائرية وذللك استجابة لعدة أسباب .

\section{ـ التحول التشريعي في مضمون رابطة الام:}

إن التوجه في توظيف حق الدم في بناء الجنسية يعد شكلا صارخًا من أشكال

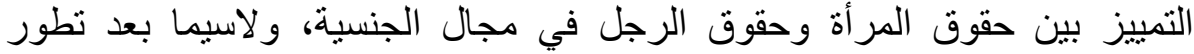

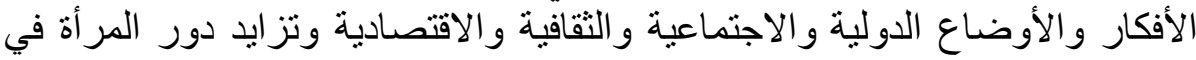

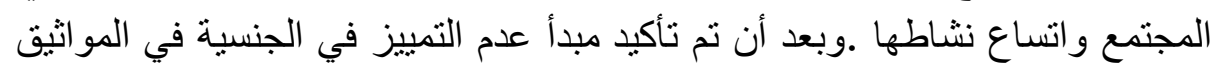

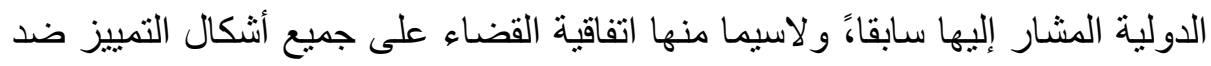

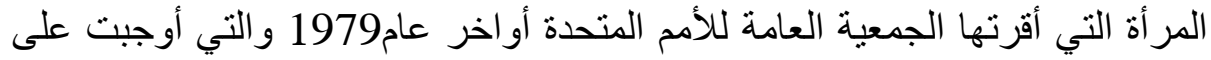
الدول الأطراف فيها، وفي الفقرة الثانية من المادة 9 منها":منح المرأة حقًا مساويًا لحق الرجل فيما يتعلق بجنسية أطفالها ."ووجدت الدول الأطر اف نفسها أمام ضرورة دولية في احترام هذا المبدأ.(14) فجعلته بعضها واحدًا من مبادئها الدستورية.ولجأ بعضها الآخر إلى تعديل قانون جنسيته الوطنية لإقرار هذا المبدأ، ولكن بأثكال

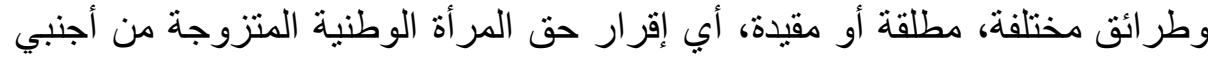

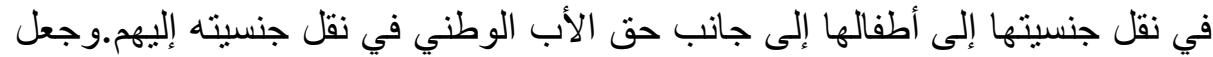


بعضها حق الدم لجهة الأم مكملا أو بديلا لحق الدم لجهة الأب في حالات محددة،

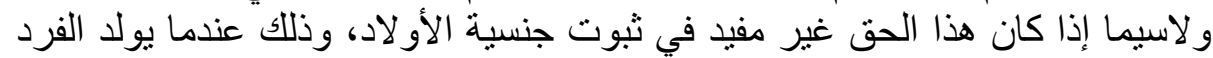

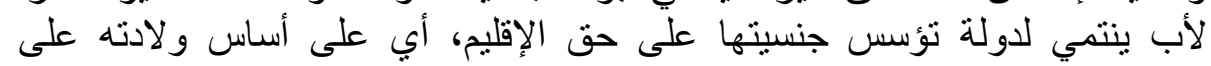

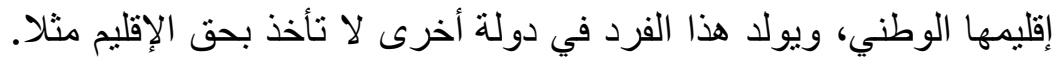

وعمدت دول أخرى إلى تقييد حق الدم لجهة الأم بشرط أن يكون المولود مولودًا في إقليم دولة الأم ولو كان للأب جنسية تتتقل إلى الابن أيضًا.

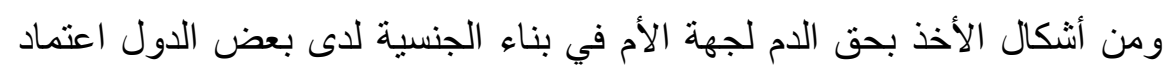

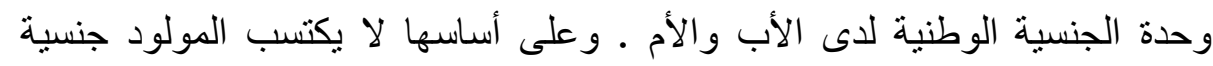

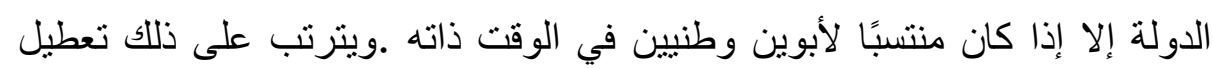

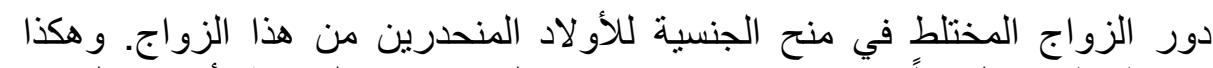

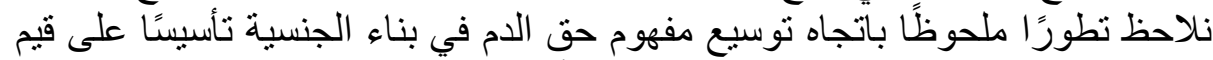

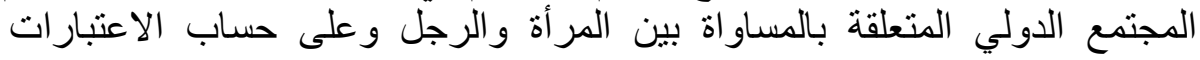
التقليدية في التلاحم الوطني و التجانس السكاني.

\section{المطلب الثاني- أسباب تثريع قاعدة إطلاق حق الام المستمد من الأم :}

لقد بينت الدراسة السابقة خروج المشرع الجزائري عن موقف التشريعات العربية

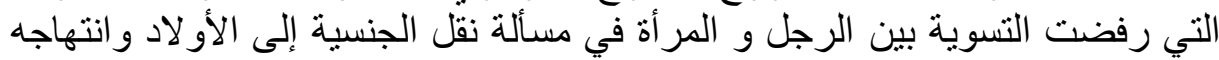

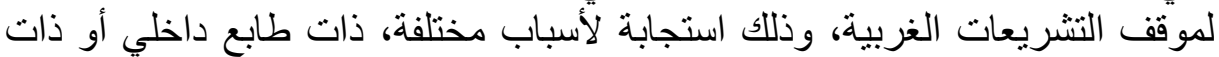

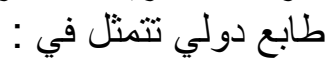

\section{فرع 1- استجابة قانون الجنسية للتحولات الاجتماعية :}

على المشرع في قانون الجنسية مراعاة مختلف المصالح، السياسية، الاقتصادية

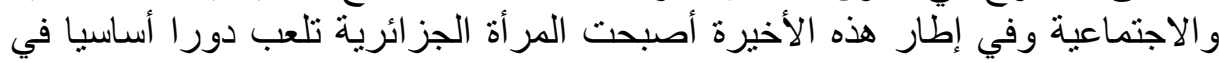

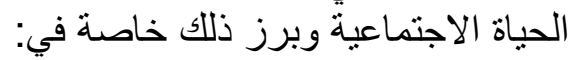

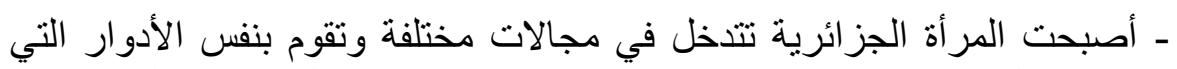

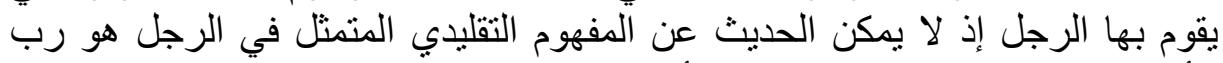

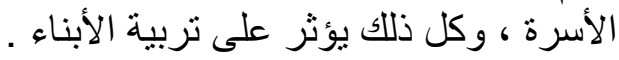

- شيوع مسألة زواج الجزائريات بالأجانب، وفي هذا الإطار يعد نقل الجنسية

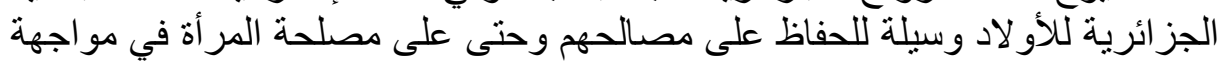
الزوج الأجنبي لاسيما في حالة عدم استمرار العلاقة الزيلة الزوجية (15) ولاّل يطرح

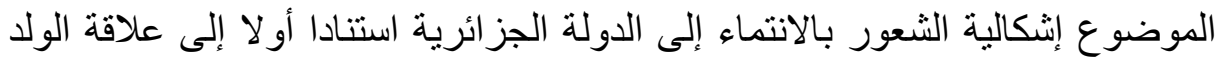

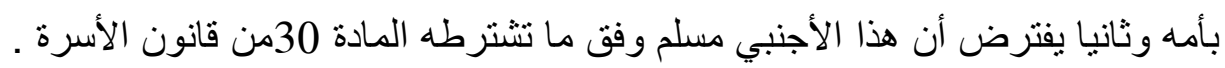


(16)

وكتأكيد على خطورة حرمان المر أة من نقل جنسيتها لأبنائها تقول الدكتور اه حفيظة

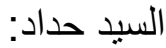

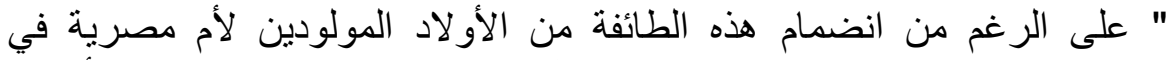

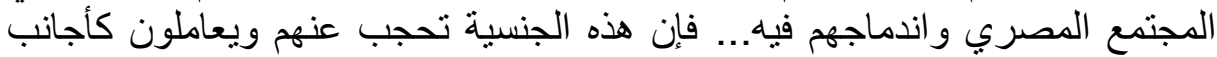

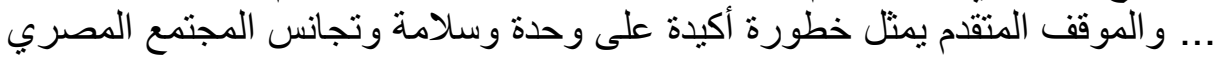
الذي لا يعترف لجزء من كيانه بالانتماء إليه قانونا.

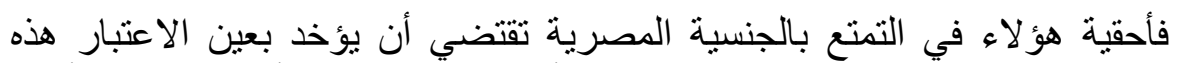

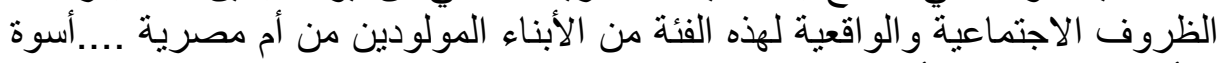

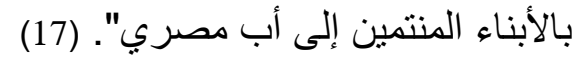
ـ تولد الوعي لدى المر أة الجزائرية وظهور الحركات النسوية التي تتادي بالمساواة

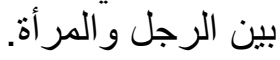

فرع- تكريس مبدأ المساواة بين الجنسين في مادة الجنسية: (18) كان لابد لهذه المادة أن تعدل استنادا أولا إلى أحكام الدستور الجزائري التي التي تقري

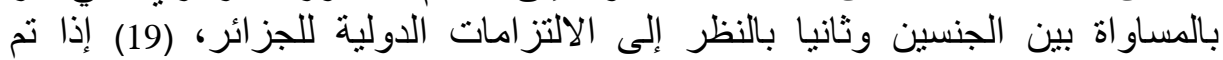

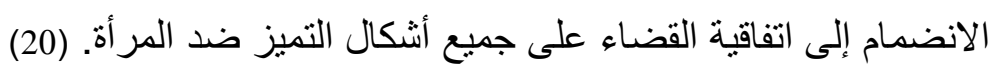
إلا أن رغبة الجزائر في الإبقاء على الطابع الاستثنائي للتمتع بالجنسية الأصلية

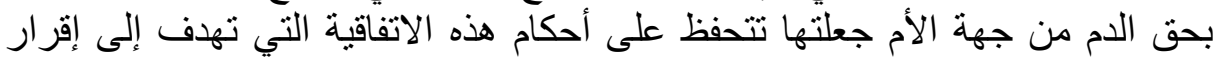

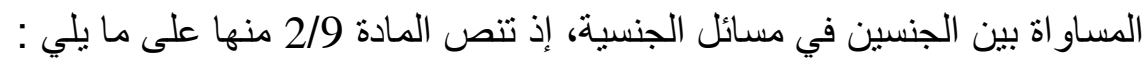
" تمنح الدول الأطر اف المرأة حقا مساويا لحق الرجل فيما يتعلق بجنسية أطفالها" وقد جاء تعديل المادة 6 إعمالا لمبدأ سمو المعاهدات الدولية ورضوخا أمام الانتقادات الواسعة التي لحقت التحفظ الجزائري على الاتفاقية ـ (21) فرع- احترام المبادئ العامة في مادة الجنسية :

استقرت الدراسات الفقهية الحديثة على مجموعة من المبادئ التي أصبحت بمثابة

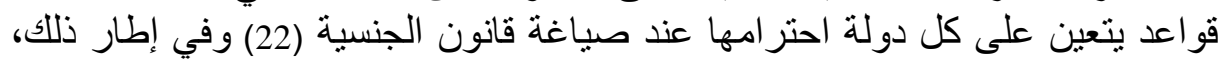

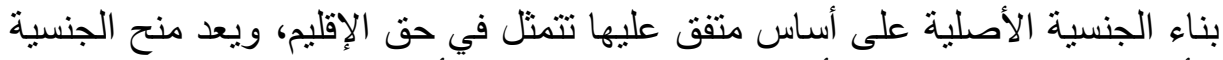

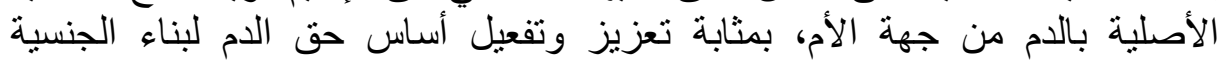

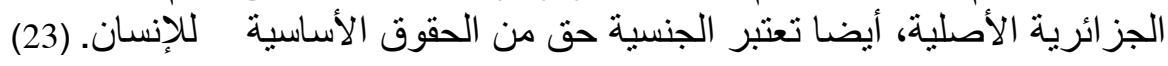




$$
\text { وتقرة 1- تعزيز أساس هذه المبادئ في: }
$$

يعبر حق الدم على الأصل العائلي أي رابطة النسب بين الولا ووالدي الديه الذي يقوم

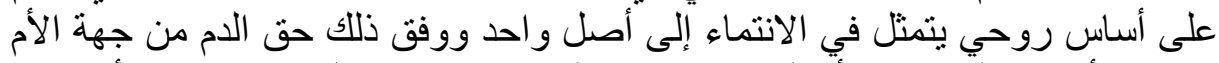

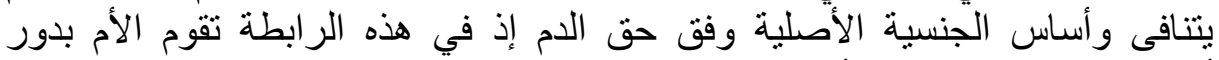

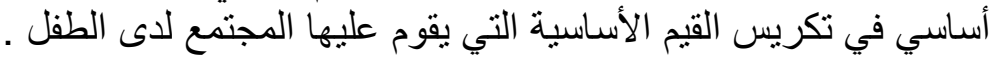

\section{فقرة2- الحق في الجنسية:}

اتجه الققه الدولي، مؤيداً بمجهودات الهيئات الدولية، إلى تقرير مبدأ ضرورة

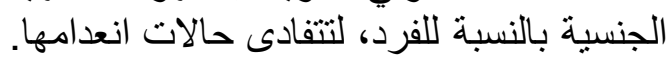

وقد توجهت هذه الجهود بإصدار وثثية الإعلان العالمي لحقوق الإنسان - في

شكل توصية - من الجمعية العامة للأمم المتحدة سنة 1948 ، وسجلت المادة 15 منها على: " أن لكل فرد الحق في جنسية واحدة،ولا يجوز حرمانه من تغيير ها أو تجريده منها بطريقة تحكمية (24) .".. وبذلك تساوي حق الفرد في الجنسية مع باقي حقوق

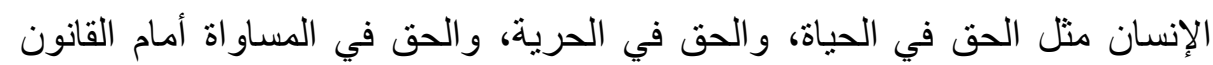

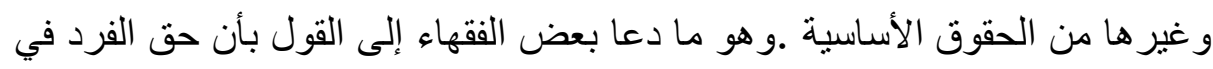

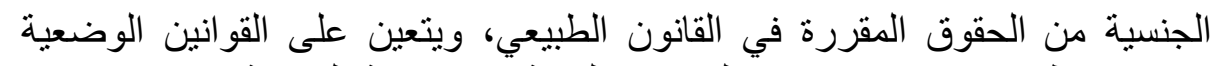

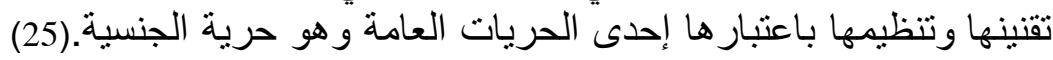
أضف إلى ذلك، أن اتفاقية حقوق الطفل التي صادقت عليها الجزائر (26) تتص في

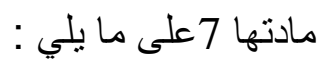
" يسجل الطفل بعد ولادته فورا ويكون له الحق منذ ولادته في اسم والحق في اكتساب الجنسية ". وكذلك اتفاقية جنسية المرأة 1957 (27) وإعلان استبعاد التمييز ضد المرأة (28) .1967

من خلال هذه النصوص، فإن الجنسية حق لكل فرد وهذا الحق يعبر عن هوية

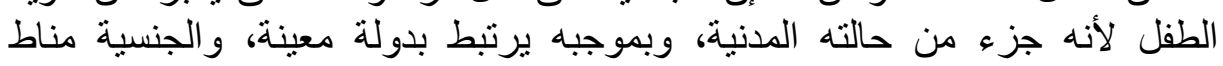

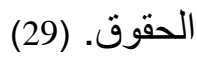


الفقرة 3 - عدم تعارض مبدأ حق المرأة في نقل جنسيتها لأبنائها مع أحكام

القوانين الوطنية: - 20 - 20

إذا كانت الدول العربية تسعى لحماية الأحكام الآمرة أو المعتبرة من النظام العام

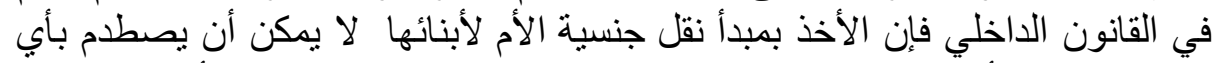

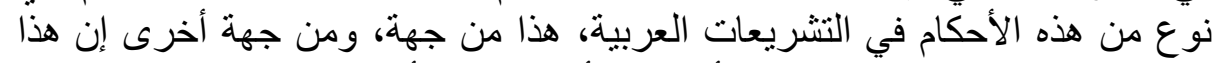

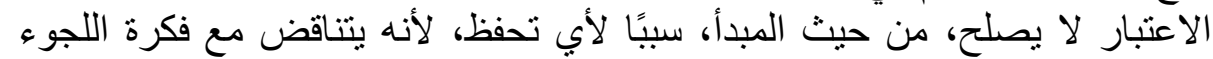

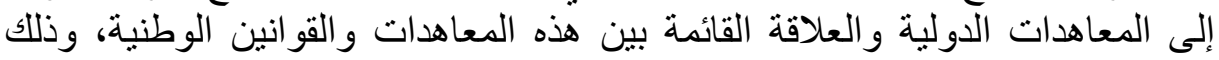

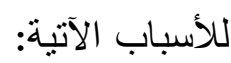

1- لأن الدول تلجأ إلى المعاهدات للتغلب على اختلاف تشريعاتها وتجاوز

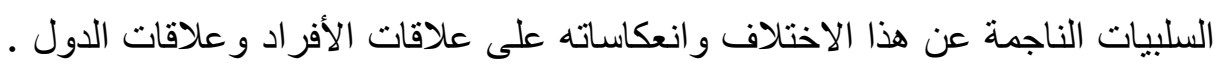

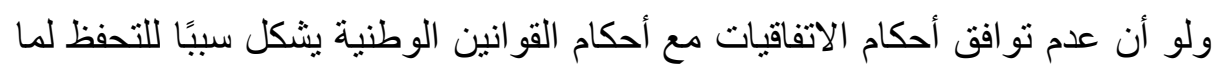

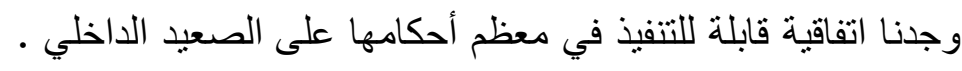

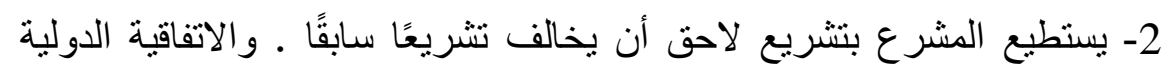

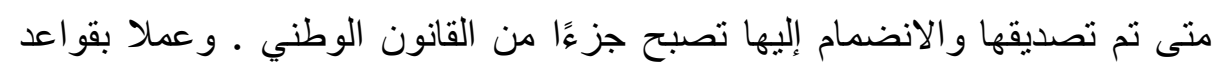
تنازع القوانين من حيث الزمان فإن القانون اللاحق ينسخ السابق ضمنًا. - الفقرة4 :عدم تعارض مبدأ حق المرأة في نقل جنسيتها لأبنائها مع مركز المرأة في التشريعات العربية:

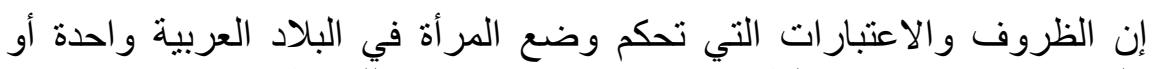

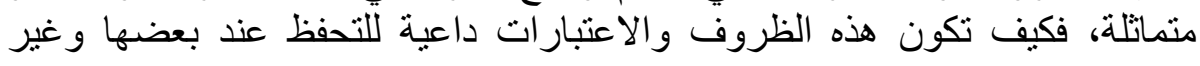

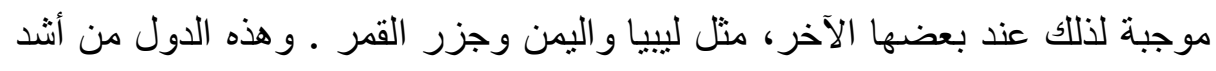

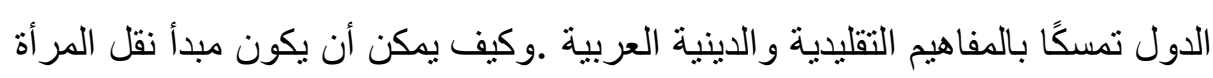

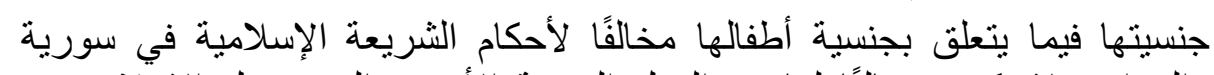

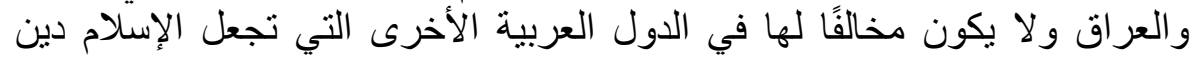

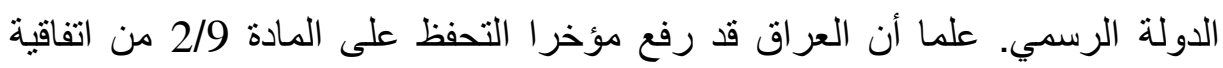
سيداو. (30)

الفقرة 5- عدم تعارض مبدأ حق المرأة في نقل جنسيتها لأبنائها مع العادات 


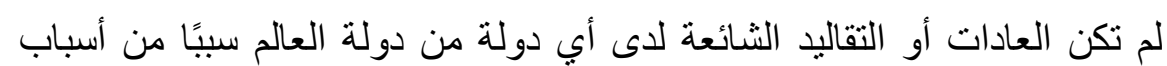

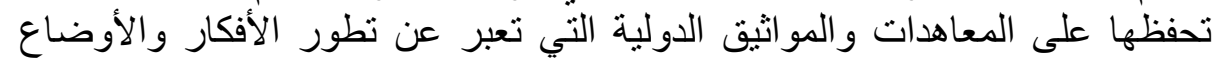

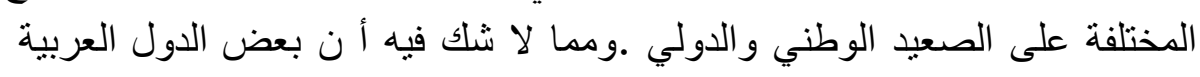

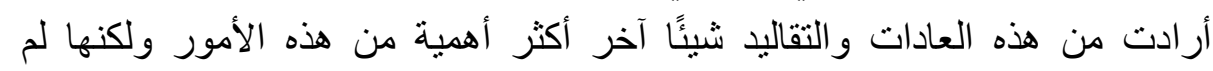

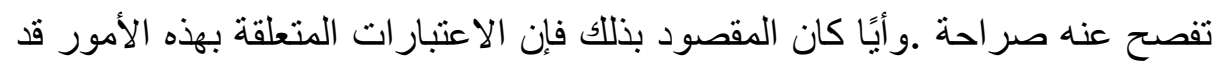

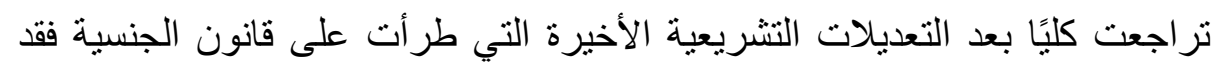

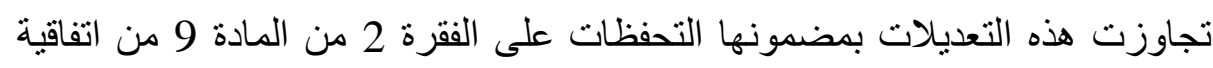

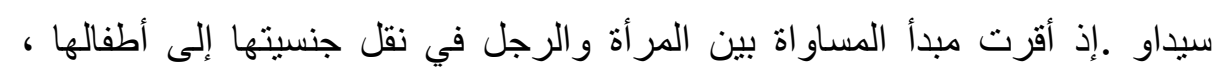

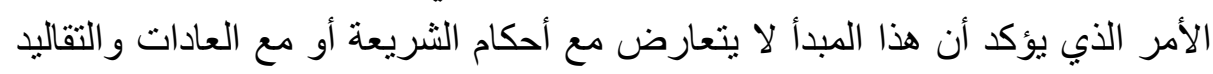
الإسلامية.

\section{الفقرة 6- عدم تعارض مبدأ حق المرأة في نقل جنسيتها لأبنائها مع الثريعة}

الإسلامية:

يقول أحد الفقهاء بصدد مسألة ثبوت الجنسية للأبناء عن طريق الانتماء لأب

$$
\text { وطني أو أم وطنية بموجب قو اعد الثريعة الإسلامية ما يأتي: }
$$

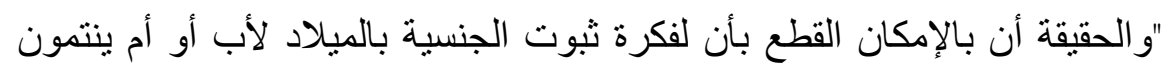

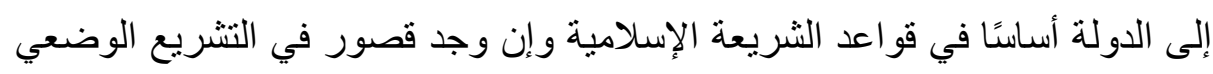

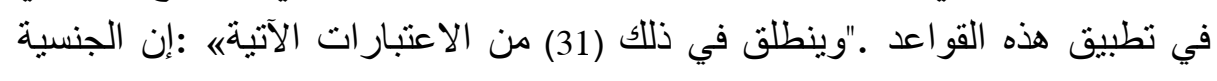

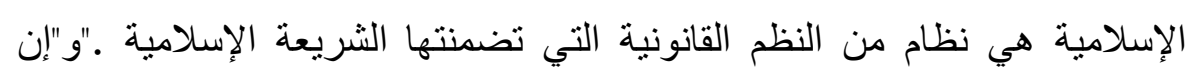

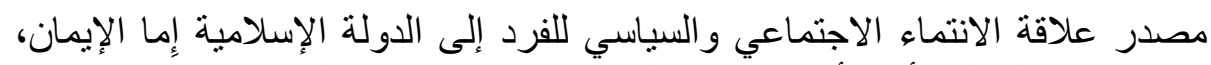

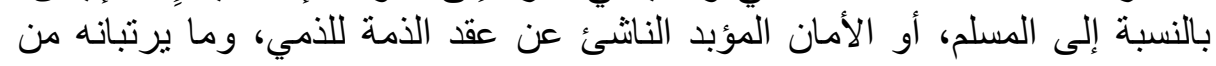

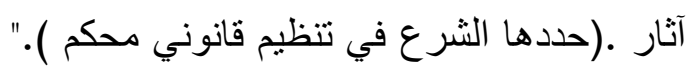

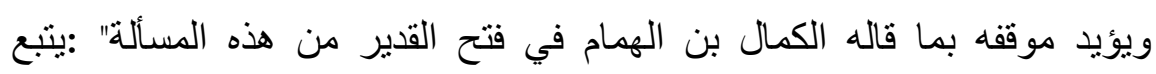

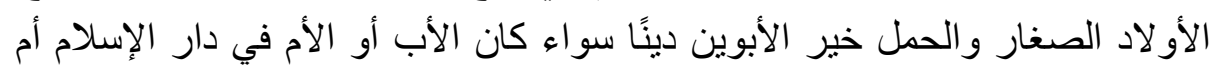

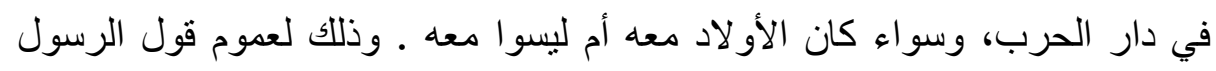

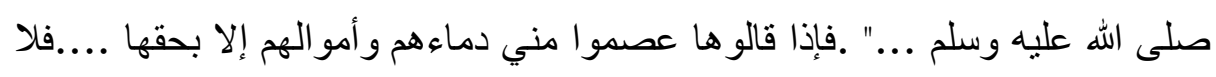
تخصيص فيه بمكان دون آخر أو لحالة دون أخرى ."ويؤكد هذا الموقف أيضًا بقول ابن القيم فيما يقتضي الحكم بإسلام الطفل" :إ ن إسلام الصبي يحصل بخمسة أشنياء 
منها ....إسلام الأبوين أو أحدهما فيتبعه الولد قبل البلوغ"

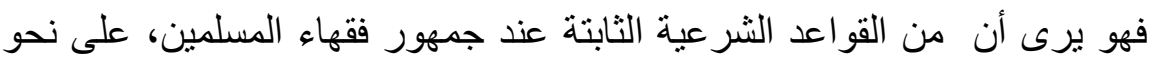

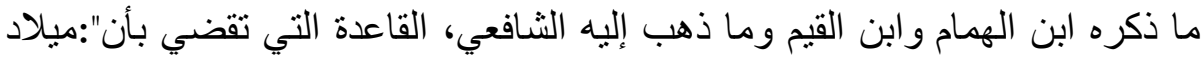

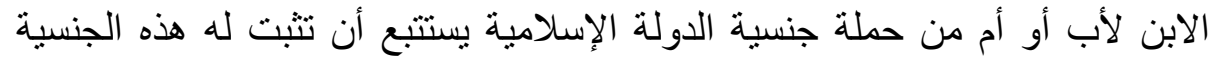

ويعلل ذلك بقوله" :إن إسلام الأب أو الأم يستتبع إسلام الابن القاصر ومن باب أولى الابن الذي يولد بعد الإسلام .ومن ثم يمتد إلى الابن انتماء و الديه بالتبعية سواء

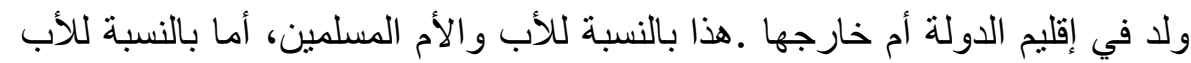

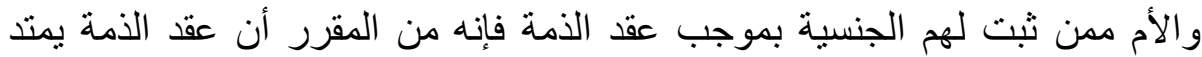

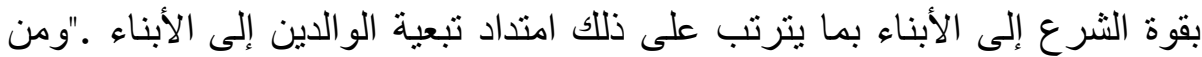

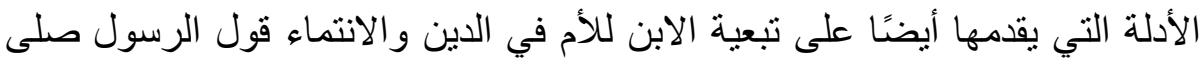

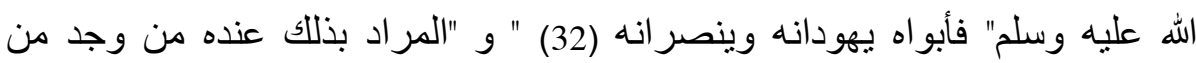
الأبوين."وعلى هذا فإنه ينتقد مع غيره من الفقهاء المسلمين المعاصرين، المؤيدين

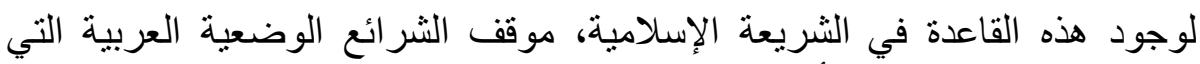

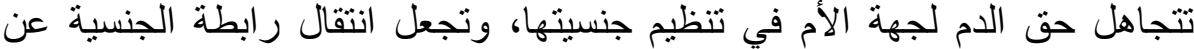

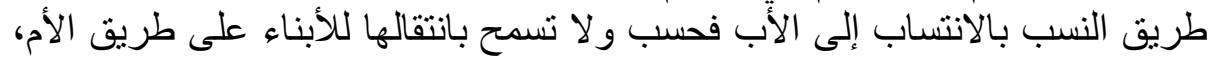
ويصفونها بتشريعات" رجعية ."لأن ذلك يثكل تنزيلا من قيمة الام من ناحية الأم

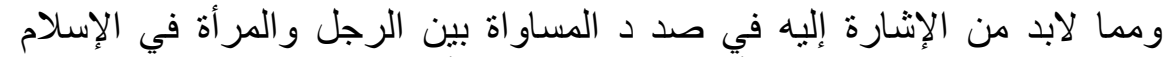

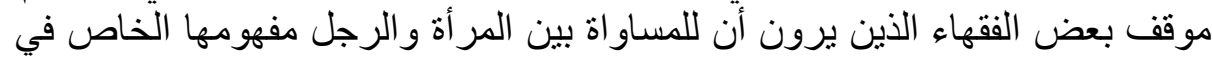

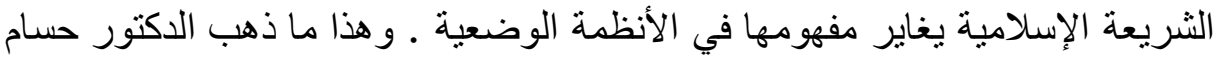

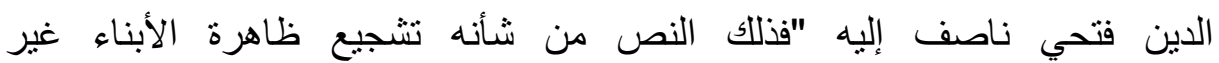
الثر عيين...." "وموقف المشرع المصري في عدم الاعتداد بصفة مطلقة بالانتساب

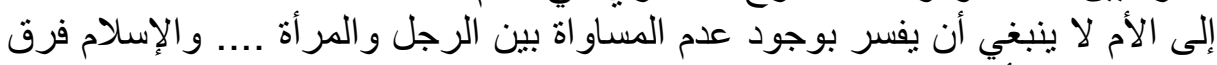

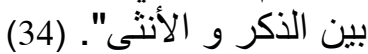

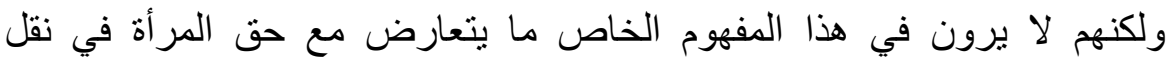

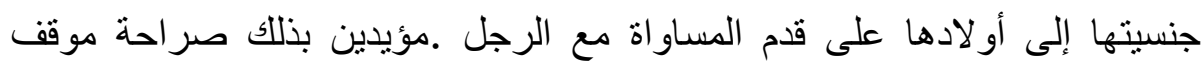
مشروع ميثاق حقوق الإنسان في الوطن العربي (35) الصادر عام 1986 بصدد هذه 


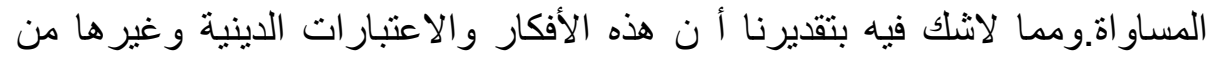

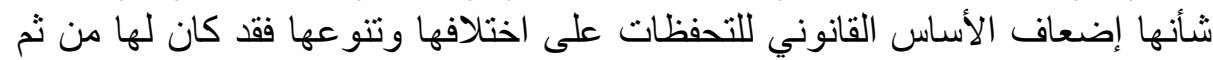

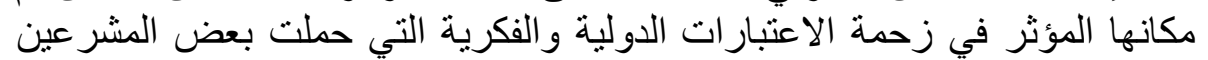

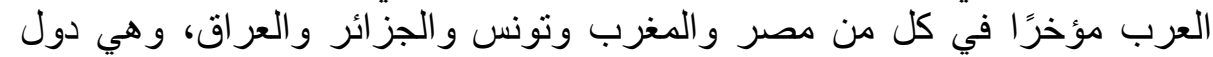

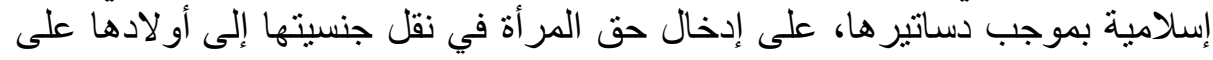

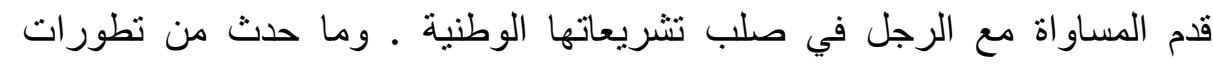
تشريعية في هذه الدول تجاوزت بمضمونها كل تحفظاتها السابقة على الفقرة الثانية من المادة 9 من اتفاقية سيداو، يدعو الدول العربية الأخرى، التي ماز الت متمسكة

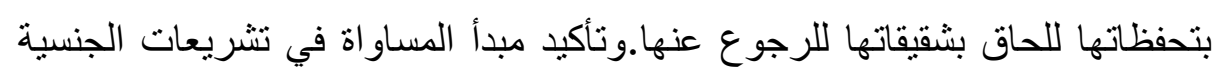

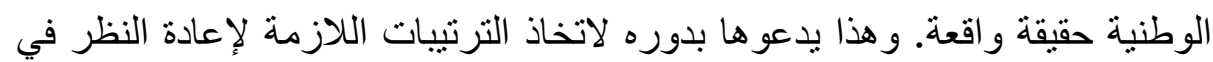

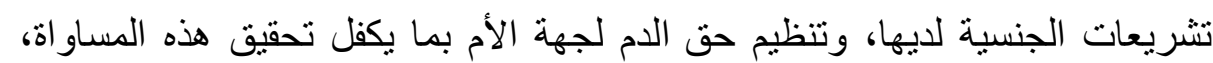

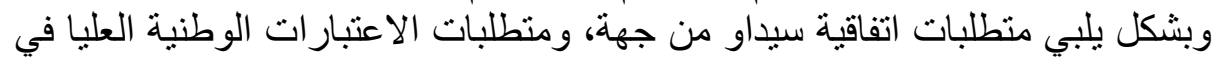
كل الدول العربية الأطر اف في هذه الاتفاقية.

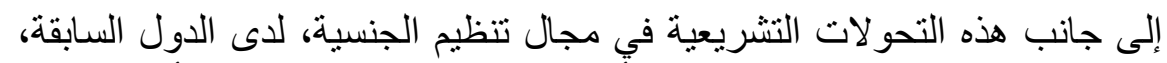

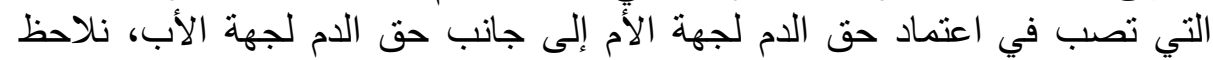

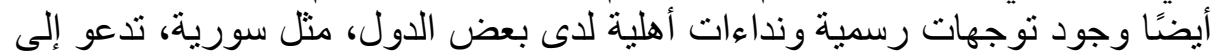

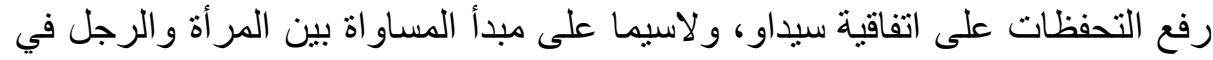

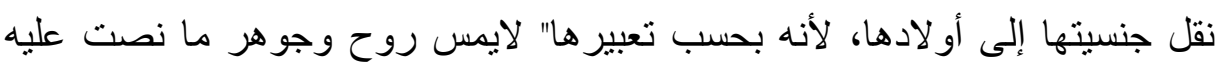

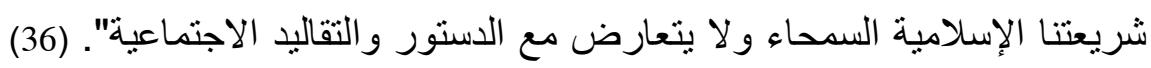
المبحث الثاني: محاذير تكريس قاعدة أطلاق حث الام من جهة الأم والحلول المقترحة.

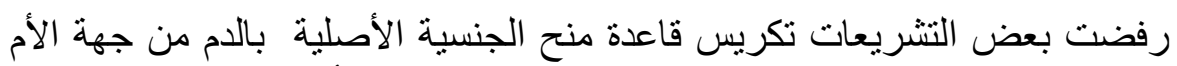

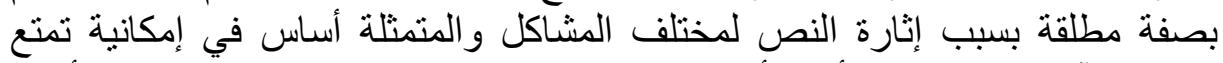

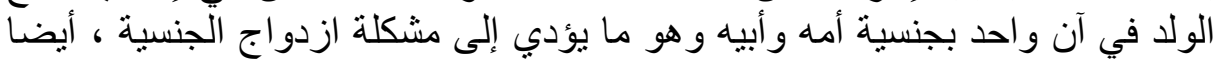

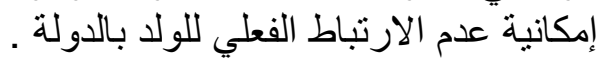

\section{المطلب 1- إمكاتية عدم ارتباط الولد بدولة الأم :}

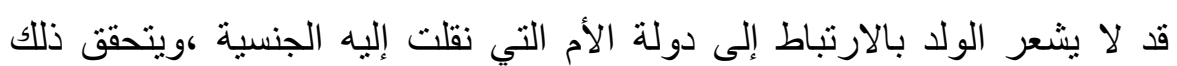

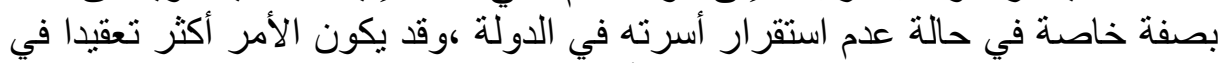

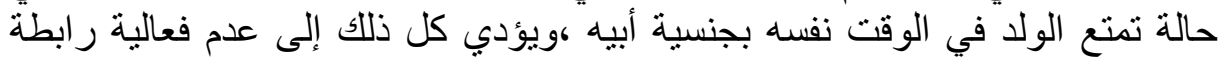

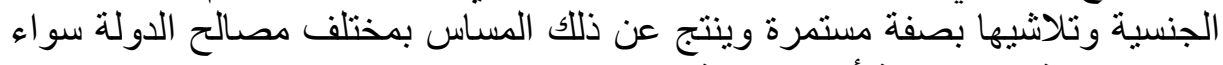




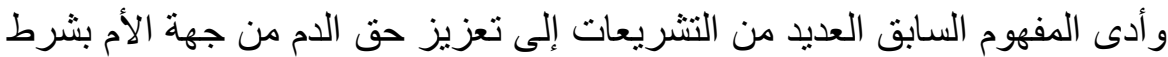

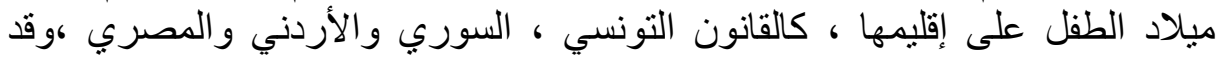
أرادت هذه الدول التوفيق بين حق الدم من جهة الأم وحق الإقليم في رابطة الإني الجنسية ويعبر هذا الأخير عن العلاقة المادية المتمثلة في الاتصال بالإقليم الإمن

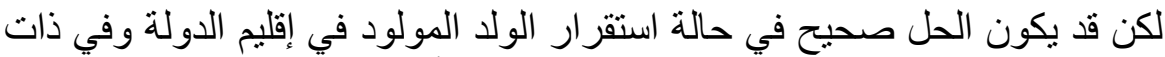

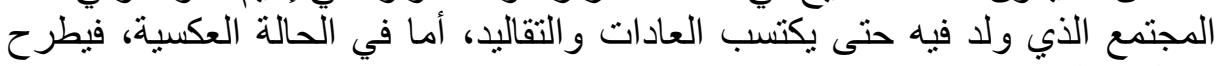
سؤال حول مدى قيمة هذا الثرط. ونرى بأنه من الأحسن ألا يثار مثل هذا المشكل استنادا إلى أساسين :

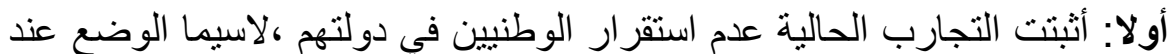

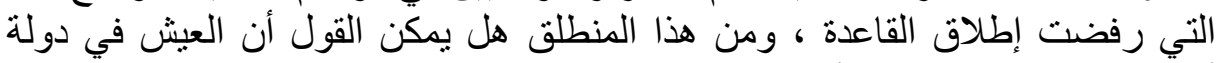
أجنبية سيؤدي حتما إلى التأثثر على مصلحة الفئ الدولة ؟

ثاتيا :هل يمكن التحدث عن المشكل نفسه بالنسبة للأولاد الذين ولدوا في دولة

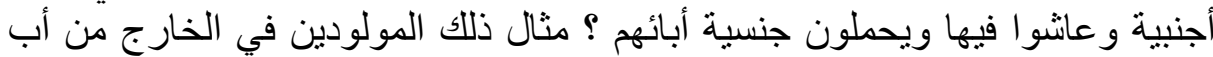

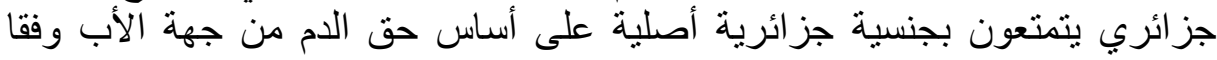
للمادة 6 من قانون الجنسية الجزائرية.

وقد سبقتنا الدول الأوروبية إلى تكريس القاعدة ولم بنتج عنها أية مشاكل من هذا

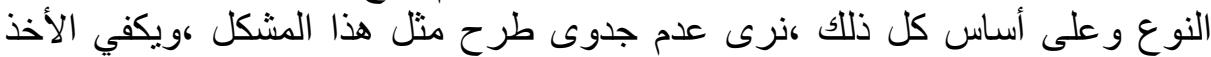

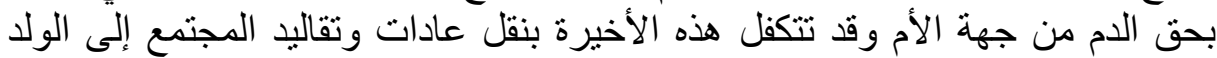

\section{المطلب2- تمتع الولا في الوقت نفسه بجنسية أجنبية :}

في هذه الحالة، يتمتع الولا بجنسية جزائرية أصلية على أساس حق الدام من جهة

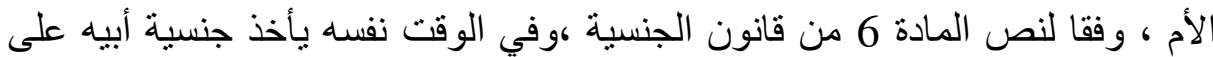

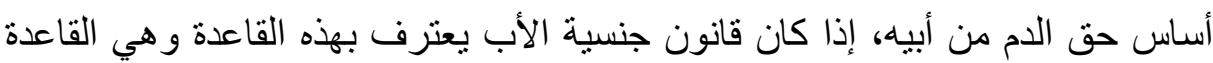

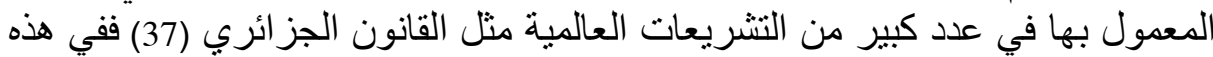

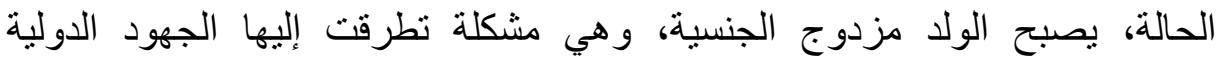

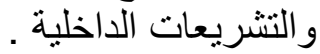

\section{فرع1- مشكلة ازدواج الجنسية:}

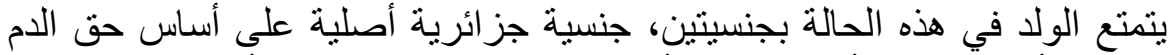

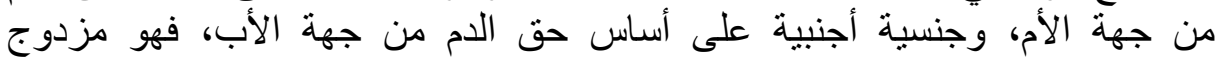




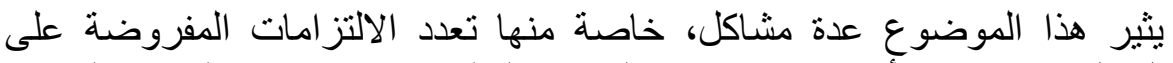

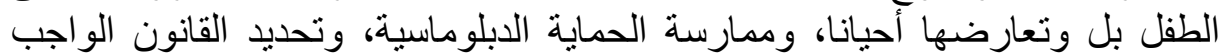

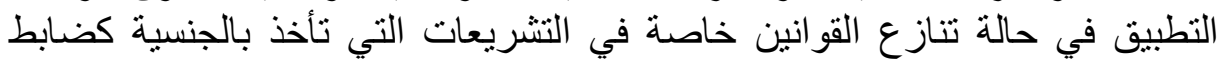
إسناد في الأحوال الثخصية على غرار القانون الجزائري مثلا. (38)

و ولا يمكن تفادي أو القضاء على هذا المشكل بصفة كلية، لكن الجهود الدولية

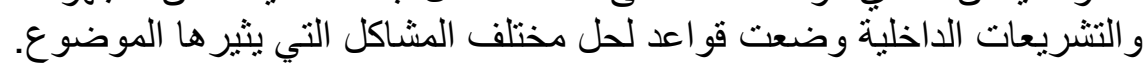
فعلى المستوى الدولي ،وخاصة في موضوع الحماية الدبلوماسية تم تقرير الجنسية

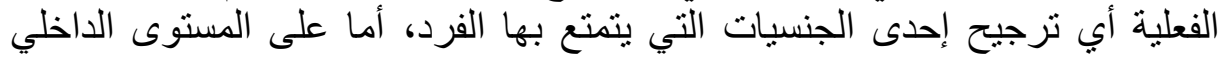

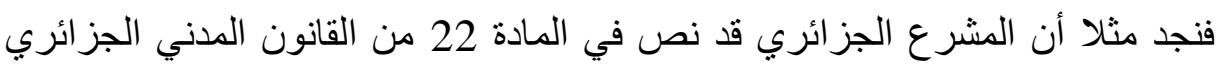

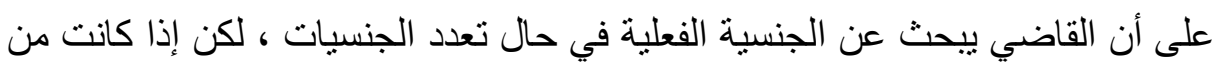

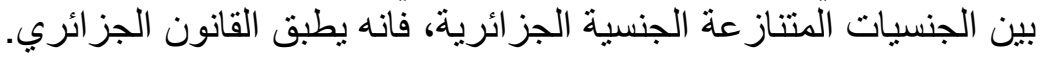

\section{فرع- إمكاتية التخلي عن جنسية ما :}

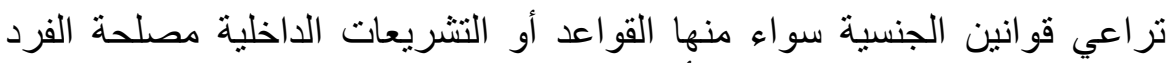

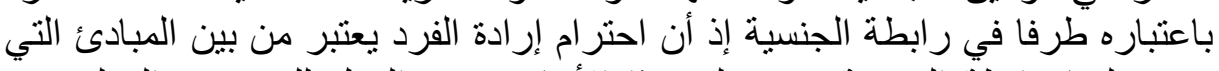

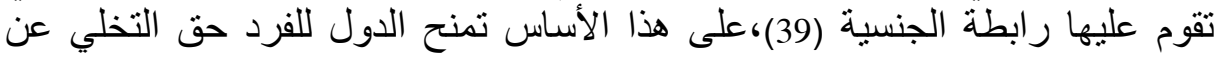

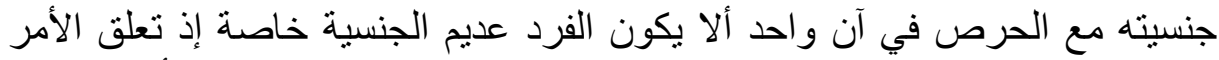

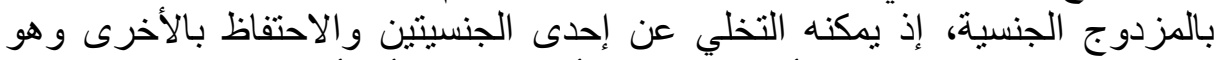

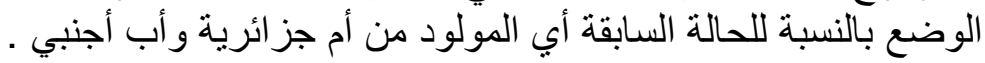

اعترف الإعلان العالمي لحقوق الإنسان في المادة 2/15 منه بحق في تغيير

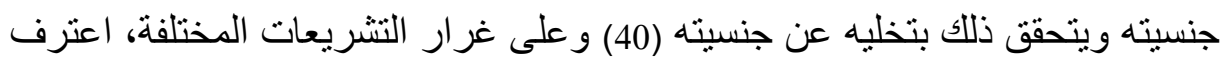

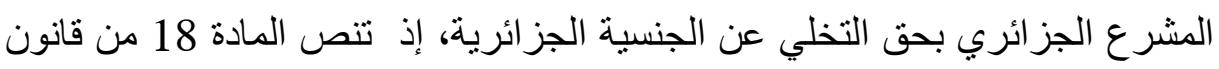

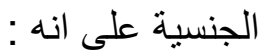

\section{"يفقد الجنسية الجزائرية :}

1- الجزائري الذي اكتسب عن طوعية في الخارج جنسية وأذن له بموجب مرسوم

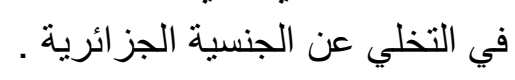

2- الجزائري، ولو كان قاصرا الذي له جنسية أصلية أجنبية وأذن له بموجب مرسوم في التخلي عن الجنسية الجزائرية.

3- المر أة الجز ائرية المتزوجة بأجنبي وتكتسب جر اء زواجها جنسية زوجها، وأذن لها بموجب مرسوم في التخلي عن الجنسية الجزائرية. 
4- الجزائري الذي يطلب التخلي عن الجنسية الجزائرية في الحالة المنصوص عليها في الفقرة الثانية من المادة 18 أعلاه.

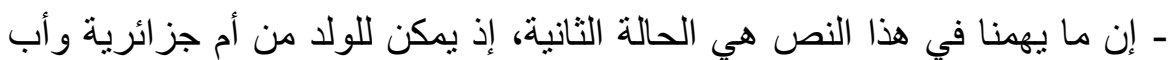

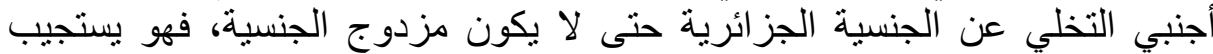
للشروط المنصوص عليها في الحالة الثانية من المادة 18، فهذا الولا جزئلئية لائريا لأنه

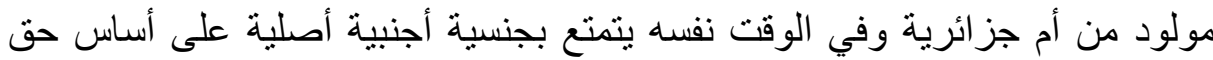

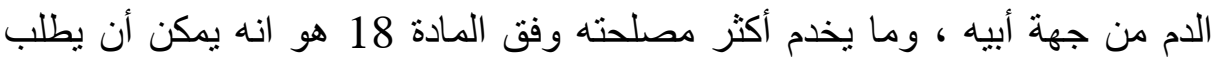
التخلي عن الجنسية الجز ائرية حتى لو كان قاصرا فيتحرر من مشكلة ازدواج الجنسية

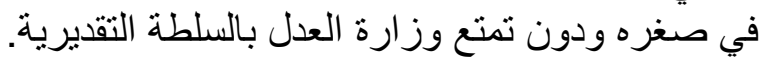

الخاتمة

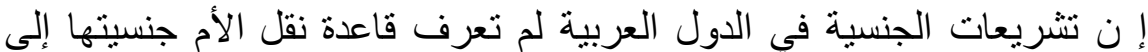
أطفالها، ولعل مرد ذللك هو هيمنة المفاهيم السائدة في القوانين الداخلية لهذه الدول، الدان.

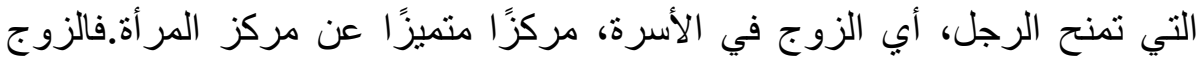
رأس الأسرة وصاحب السلطة العليا فيها ـ. وبارادته وحدها يمكن فصم عرى الزوجية وقانون الزوج هو القانون واجب التطبيق في كل مسائل الأسرة المتعلقة

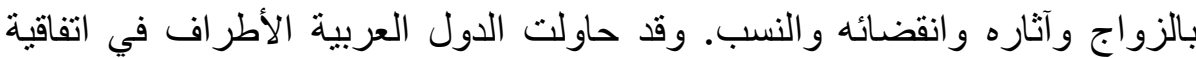
سيداو، باستثناء كل من اليمن وجزر القمر وليبيا،التمسك بالوضع التشريعي ولتهي السائد لديها بشأن الجنسية عندما تحفظت على الفقرة الثانية من المادة 9 من الاتفاقية بموجب الصكوك التشريعية التي تضمنت التصديق عليها ـوانطلقت هذه الدول في تعليل تحفظاتها على نص الفقرة 2 المشار إلبها سابقًا من اعتبار ات متعددة ومختلفة دينية وسياسية وتشريعية واجتماعية تختلف باختلاف الدول المتحفظة.

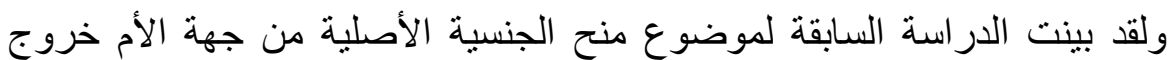
المشرع الجزائري في سنة 2005 عن الطابع الاستثنائي المكرس في التشريعات التهاته

$$
\text { العربية وانتهاجه لموقف الدول الغربية. }
$$

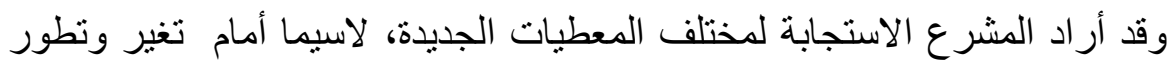

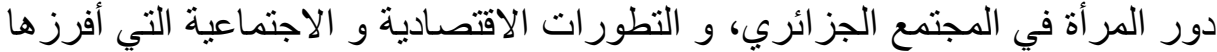

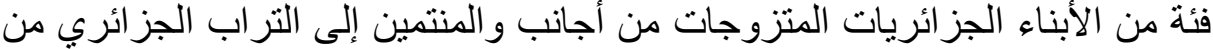

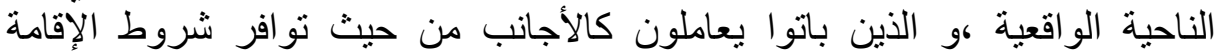
القانونية و يجدون عر اقيل في الالتحاق بمناصب العاتِ العمل و غير ها. 


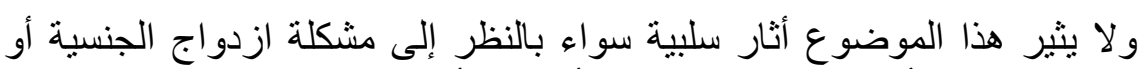

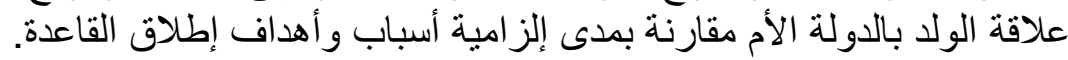

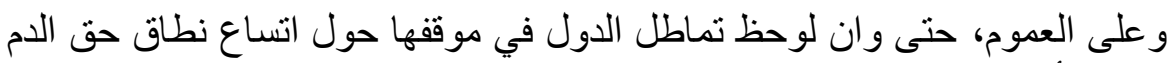

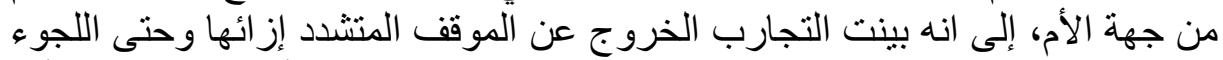

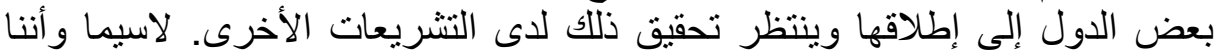

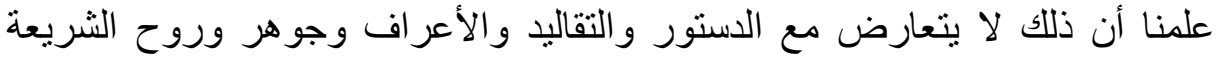

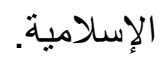

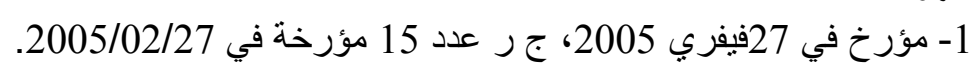

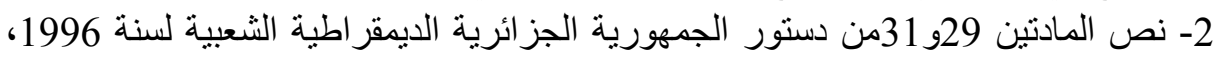

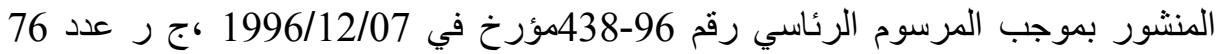

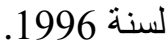
3- قامت الجزائر برفع التحفظ الذي أبدته حول المادة 09 /2من الاتفاقية تبعا لتعديل قانون

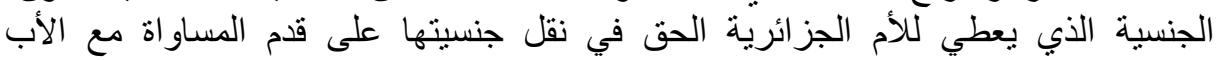

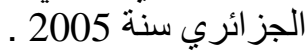
بموجب المرسوم الرئاسي رقم 08 - 426 مؤرّخ في 28 ديسمبر سنة 2008 الجريدة

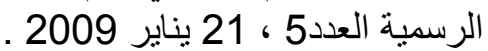

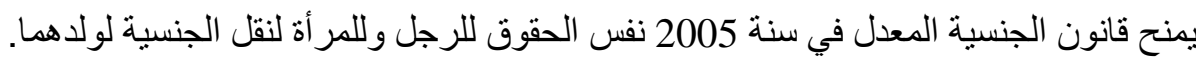

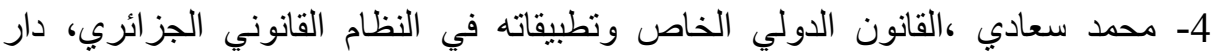
الخلدونية، الجزائر، دت، دط، ص الثرب 252.

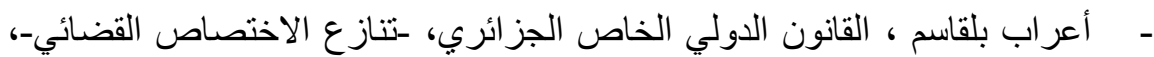

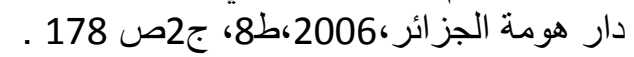

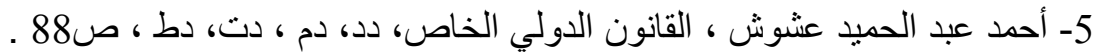

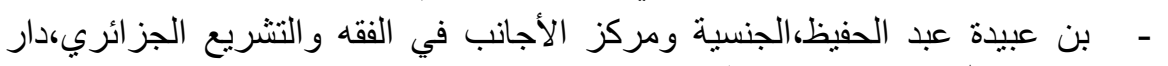

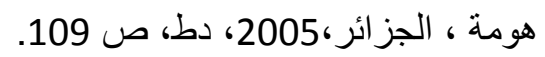
6- هثام خالد،اكتساب الجنسية الأصلية بالميلاد لأب وطني، دراسة مقارئ مقارنة في قانون الجنسية

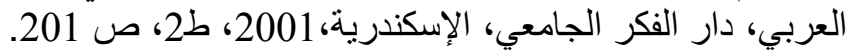

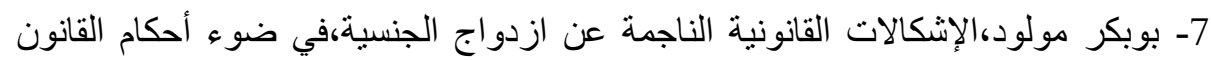

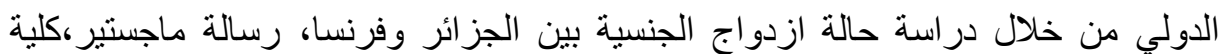

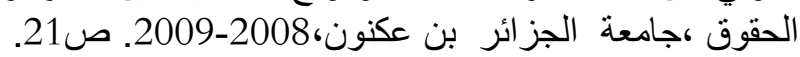

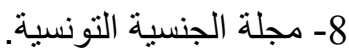

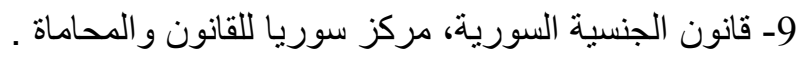
10- قانون الجنسية الأردنية، قانون رقم 6 لسنة 1954. 
11- القانون رقم 26 لسنة 1975 المتضمن قانون الجنسية المصري.

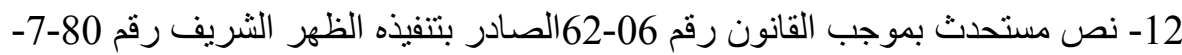

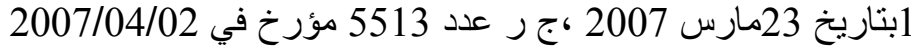

13- انظر في ذللك المادة 18 من القانون المدني الفرنسي.

وكانت المادة 17 من قانون الجنسية الفرنسية تنص الفئ على انه:

«Est français l'enfant dans 1 un des parents au français »v :idib.

14- براجع :هشام خالد، أهم مشكلات قانون الجنسية العربي، منشأة المعارف،

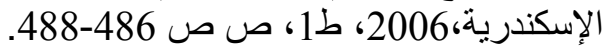

15- سهام حواس، "جزائريات يشدن بالقرار ويعتبرنه بداية لحل مشاكل فئة كبيرة منهن" ، جريدة الحوار رابط www.djazairess.com

16- محمد طيبة، الجديد في قانون الجنسية الجزائرية و المركز القانوني لمتعدد الجنسيات، دار

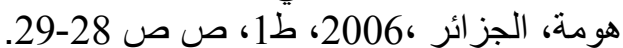
17- لتقصيل في الموضوع يراجع:

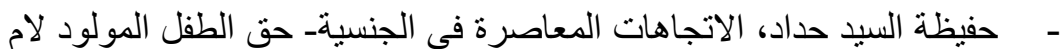

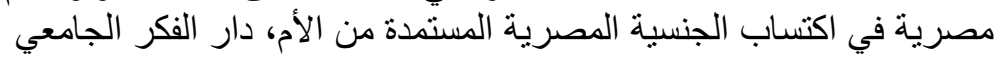

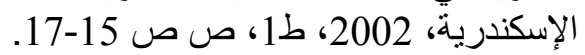
18- لتفصيل في الموضوع يراجع:

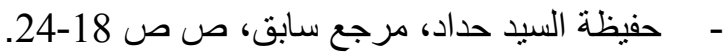

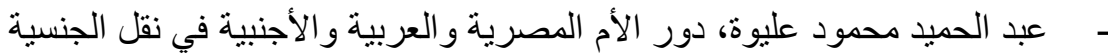

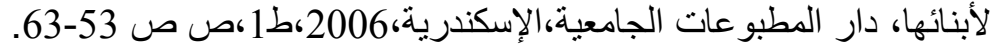

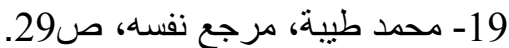

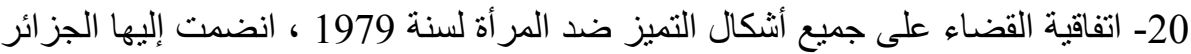

بتحفظ بموجب المرسوم الرئاسي رقم 961-51المؤرخ في 22 جانفي 1996 ،ج ر عدد 6 لسنة 1996.

21- 21 انظر على سبيل المثنال

Observations finales du comité sur l'élimination de la discrimination à l'égard des femmes;a54/38 ; Paris ;41.94 20ème session ;Algérie

فقد أوصت هذه اللجنة بضرورة سحب التحفظ الجزائري على هذه الاتفاقية لكونه يمس

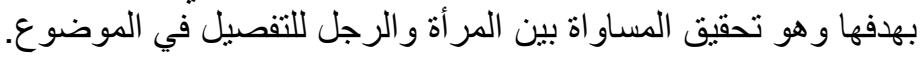

22- Pierre Mayer, Droit international privé, 5ème Ed. Broché ; 1996 ; pp562-565.

23- لتفصيل في الموضوع ير اجع:

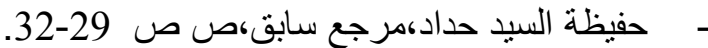

24- الإعلان العالمي لحقوق الإنسان لسنة 1948 الصادر عن الجمعية العامة للأمم المتحدة،

انضمت إليها الجزائر بموجب المقادة الإندان لينان 11 من دستور 1993

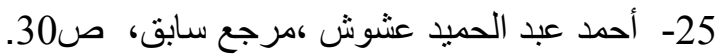




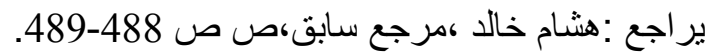

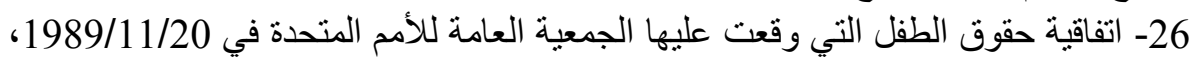

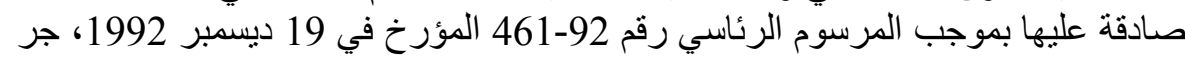

عدد 91 لسنة علة الفئة 1992

27- اتفاقية جنسية المر أة المتزوجة التي وقعت عليها الجمعية العامة للأمم المتحدة في

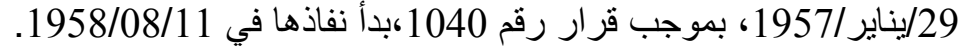

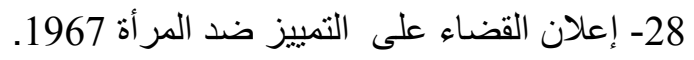

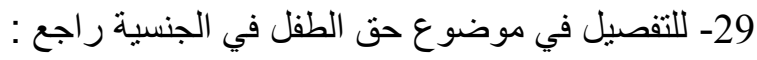

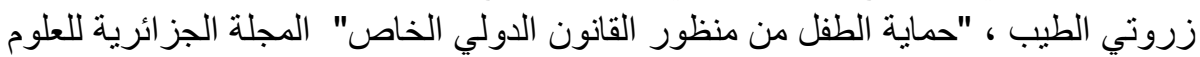

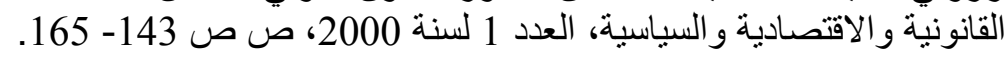

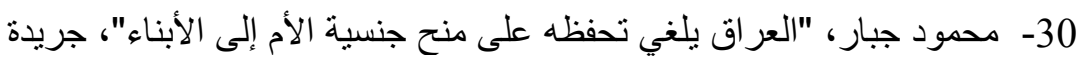

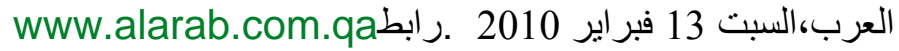

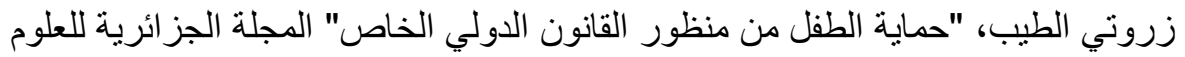

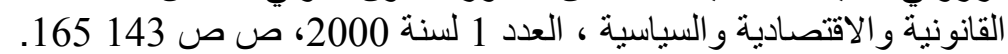

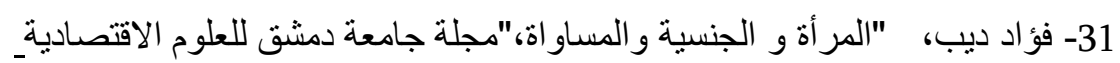

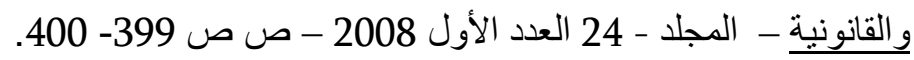

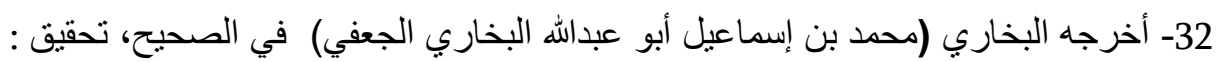

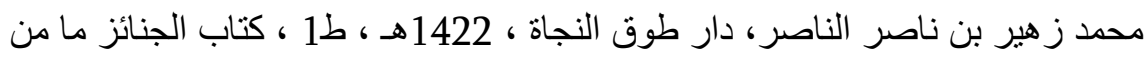

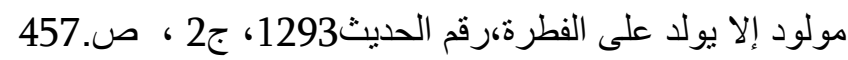
33- للتفصيل في الموضوع ير اجع:

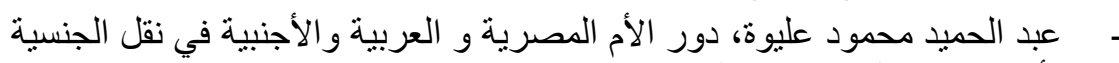

لأبنائها، دار المطبو عات الجامعية، الإسكندرية، دالة 2006، ط1، ص صل صل 14-52.

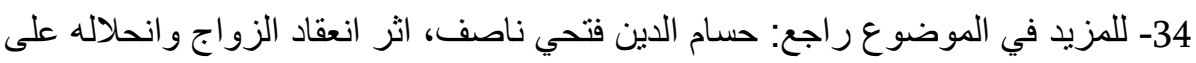

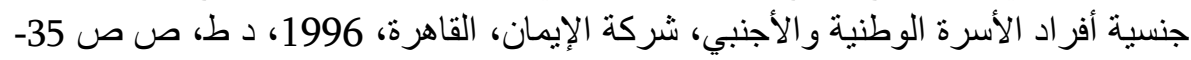

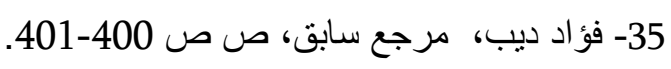

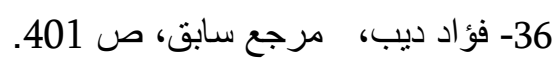

37- قانون الجنسية الجز ائري.

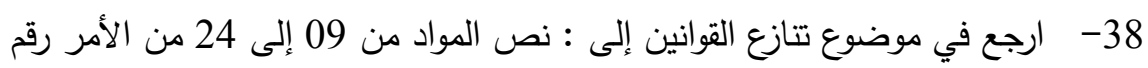

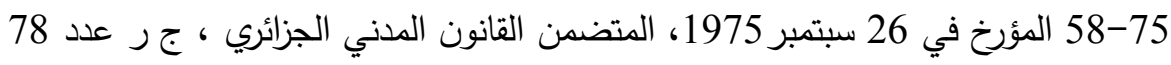

لسنة 1975 ، المعدل والمتمم بموجب القانون رقم 05-01 مؤرخ في 20جوان 2005 ج ر

عدد 44سنة 2005.

Issad Mohand, droit international privé: Les règles de conflits, O.P.U, Alger, 1986. 
39- للتفصيل في الموضوع راجع :

Vincent Heuzé, Pierre Mayer ; Droit international privé, 7ème èd , Montchrestien ; Paris ;2001;p601.

40- في موضوع تعدد الجنسيات أمام القاضي الجزائري راجع زروتي الطيب ، الوسيط في

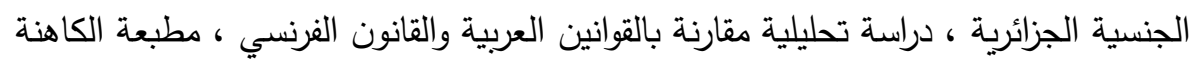

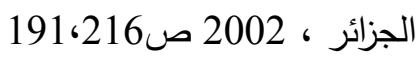

\section{المراجع}

ـ أعر اب بلقاسم ،القانون الدولي الخاص الجزائري، -تنازع الاختصاص القضائي-،دار هومة

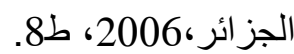

ـ أحمد عبد الحميد عشوش ،القانون الدولي الخاص، دد،دم ،دت،دط.

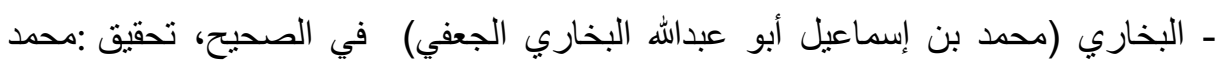

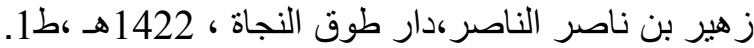

- زروتي الطيب، الوسيط في الجنسية الجزائرية ، دراسة تحليلية مقارنة بالقوانين العربية و القانون الفرنسي، مطبعة الكاهنة الجزائر، - محمد طيبة،الجديد في قانون الجنسية الجزائرية والمركز القانوني لمتعدد الجنسيات، دار

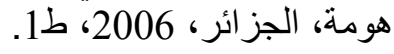

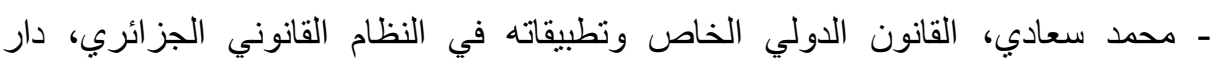

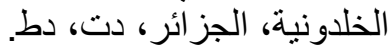


- حسام الدين فتحي ناصف، اثر انعقاد الزواج و انحلاله على جنسية أفراد الأسرة الوطنية و الأجنبية، شركة الإيمان، القاهرة، نأن، 1996، دط.

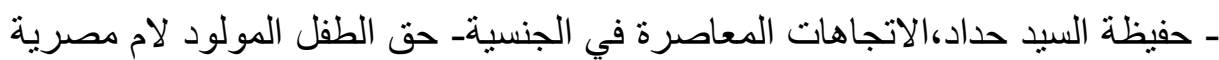

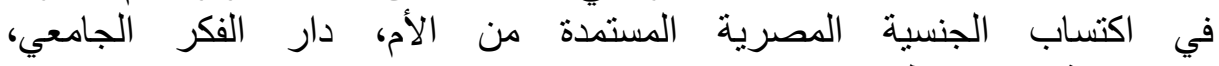

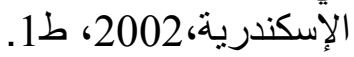

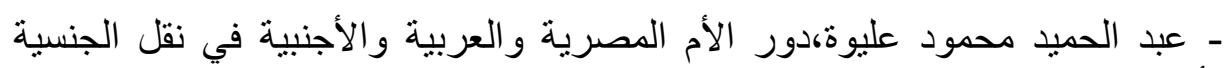

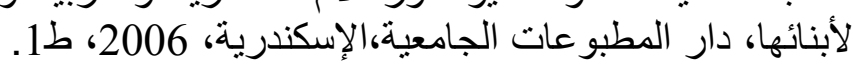
- هشام خالد، أهم مشكلات قانون الجنسية العربي، منشأة المعارف، الإسكندرية، .1. 2006 - هشام خالد،اكتساب الجنسية الأصلية بالميلاد لأب وطني،در اسة مقارنة في فانون

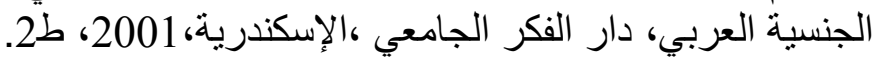

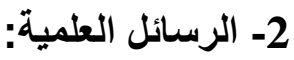

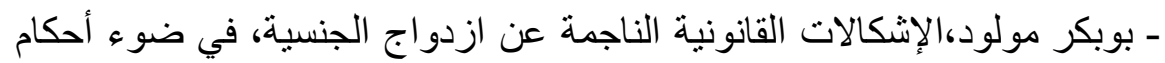

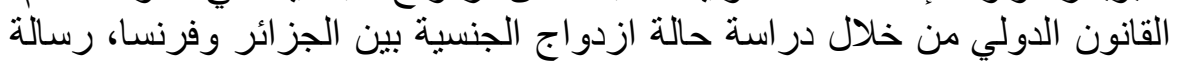

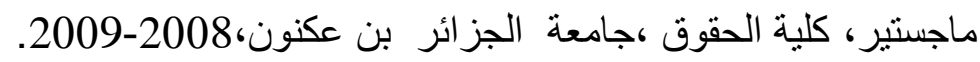

\section{3-القوانين:}

- دستور الجمهورية الجزائرية الديمقراطية الثعبية لسنة 1996، المنشور بموجب المرسوم

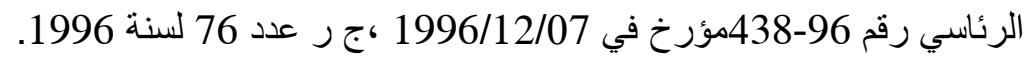
ـ أمر رقم 05 -01 مؤرخ في 27 فبراير 2005 يعدل ويتمم الأمر رقم 86 - 80 - 70 المؤرخ في 15 ديسمبر 1970و المتضمن قانون الجنسية الجزائرية.

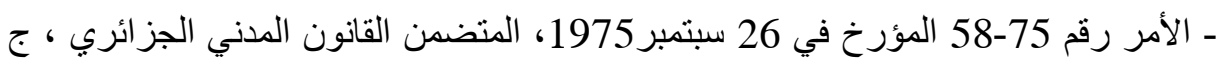

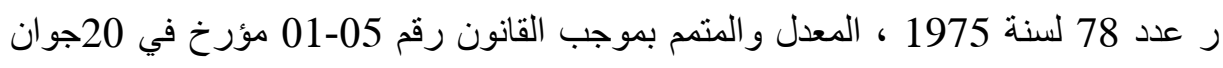

$$
2005 \text { ج ر عدد 44لسنة } 2005 .
$$

ـالمرسوم الرئاسي رقم 08 - 426 مؤرّخ في 200ديسمبر سنة 2008 المنضمن التحفظ على المادة2/9 من اتفاقية سيداو. - مجلة الجنسية التونسية الفية

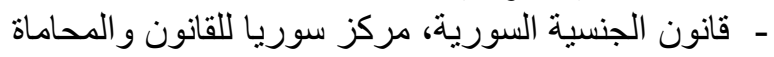
ـ ق قانون الجنسية الأردنية، قانون رقم 6 لسنة 1954. 
ـ القانون رقم 26 لسنة 1975 المتضمن قانون الجنسية المصري. - القانون رقم 06-62الصادر بتنفيذه الظهر الثريف رقم 80-7-19بتاريخ 23مارس ، جر عد 5513 مؤرخ في - القانون المدني الفرنسي

\section{4-الوثائق الدولية :}

-اتفاقية القضاء على جميع أشكال التميز ضد المرأة لسنة 1979 ، انضمت إلبها الجزائر بتحفظ بموجب المرسوم الرئاسي رقم 96-51المؤرخ في 22 جانفي 1996 ،ج ر عددكلسنة

-الإعلان العالمي لحقوق الإنسان لسنة 1948 الصادر عن الجمعية العامة للأمم المتحدة، انضمت إليها الجزائر بموجب المادة 11 من دستور 1993 ـ الإسيان - اتفاقية حقوق الطفل التي وقعت عليها الجمعية العامة للأمم المتحدة في

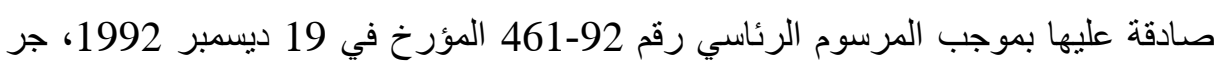
عدد 91 لسنة 1992. - اتفاقية جنسية المرأة المتزوجة التي وقعت عليها الجمعية العامة للأمم المتحدة في

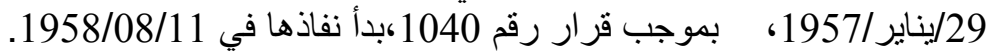
- - إعلان القضاء على التمييز ضد المر أة 1967.

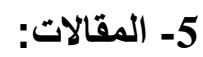

-زروتي الطيب ، حماية الطفل من منظور القانون الدولي الخاص " المجلة الجزائرية للعلوم القانونية و الاقتصادية و السياسية ، العدد 1 لسنة 2000. - فؤاد ديب، المرأة و الجنسية و المساو اة، مجلة جامعة دمثق للعلوم الاقتصادية و القانونية ـ المجلد - 24 العدد الأول 2008 ـ محمود جبار ، العراق يلغي تحفظه على منح جنسية الأم إلى الأبناء، جريدة العرب، السبت

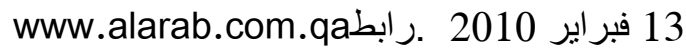
-سهام حواس، جزائريات يشدن بالقرار ويعتبرنه بداية لحل مشاكل فئة كبيرة منهن ،جريدة الحوار رابطwww.djazairess.com 